Nova Southeastern University

\title{
Particle Formation and Growth From Ozonolysis of $a$-pinene
}

\author{
William Hoppel \\ Naval Research Laboratory \\ James Fitzgerald \\ Naval Research Laboratory \\ Glendon Frick \\ Naval Research Laboratory \\ Peter F. Caffrey \\ Naval Research Laboratory \\ Louise Pasternack \\ Naval Research Laboratory \\ See next page for additional authors
}

Follow this and additional works at: https://nsuworks.nova.edu/cnso_chemphys_facarticles Part of the Environmental Chemistry Commons

\section{NSUWorks Citation}

Hoppel, W., Fitzgerald, J., Frick, G., Caffrey, P. F., Pasternack, L., Hegg, D. A., Gao, S., Leaitch, W. R., Shantz, N., Cantrell, C., Albrechcinski, T., Ambrusko, J., \& Sullivan, W. (2001). Particle Formation and Growth From Ozonolysis of $\alpha$-pinene. Journal of Geophysical Research: Atmospheres, 106, (D21), 27603 - 27618. https://doi.org/10.1029/2001JD900018. Retrieved from https://nsuworks.nova.edu/cnso_chemphys_facarticles/142 
Authors

William Hoppel, James Fitzgerald, Glendon Frick, Peter F. Caffrey, Louise Pasternack, Dean A. Hegg, Song

Gao, W. Richard Leaitch, Nicole Shantz, Chris Cantrell, Thomas Albrechcinski, John Ambrusko, and William Sullivan 


\title{
Particle formation and growth from ozonolysis of $\alpha$-pinene
}

\author{
William Hoppel, ${ }^{1,2}$ James Fitzgerald, ${ }^{1}$ Glendon Frick, ${ }^{1}$ Peter Caffrey, ${ }^{1}$ \\ Louise Pasternack, ${ }^{1}$ Dean Hegg, ${ }^{3}$ Song Gao, ${ }^{3}$ Richard Leaitch, ${ }^{4}$ \\ Nicole Shantz, ${ }^{4}$ Christopher Cantrell, ${ }^{5}$ Thomas Albrechcinski, ${ }^{6}$ \\ John Ambrusko, ${ }^{6}$ and William Sullivan ${ }^{6}$
}

\begin{abstract}
Observations of particle nucleation and growth during ozonolysis of $\alpha$-pinene were carried out in Calspan's $600 \mathrm{~m}^{3}$ environmental chamber utilizing relatively low concentrations of $\alpha$-pinene (15 ppb) and ozone (100 ppb). Model simulations with a comprehensive sectional aerosol model which incorporated the relevant gas-phase chemistry show that the observed evolution of the size distribution could be simulated within the accuracy of the experiment by assuming only one condensable product produced with a molar yield of $5 \%$ to $6 \%$ and a saturation vapor pressure (SVP) of about $0.01 \mathrm{ppb}$ or less. While only one component was required to simulate the data, more than one product may have been involved, in which case the one component must be viewed as a surrogate having an effective SVP of $0.01 \mathrm{ppb}$ or less. Adding trace amounts of $\mathrm{SO}_{2}$ greatly increased the nucleation rate while having negligible effect on the overall aerosol yield. We are unable to explain the observed nucleation in the $\alpha$-pinene/ozone system in terms of classical nucleation theory. The nucleation rate and, more importantly, the slope of the nucleation rate versus the vapor pressure of the nucleating species would suggest that the nucleation rate in the $\alpha$-pinene/ozone system may be limited by the initial nucleation steps (i.e., dimer, trimer, or adduct formation).
\end{abstract}

\section{Introduction}

Approximately $1150 \mathrm{Tg} \mathrm{C} \mathrm{yr}^{-1}$ of volatile organic compounds (VOC) are estimated to be emitted into the atmosphere by vegetation [Guenther et al., 1995], of which about $11 \%$ is estimated to be in the form of monoterpenes. $\alpha$ pinene is one of the most abundant, if not the most abundant, of the monoterpenes. Secondary organic aerosol (SOA) is formed when VOC gas-phase oxidation products have sufficiently low vapor pressures to condense, causing an increase in the mass loading of particulate matter in the atmosphere. $\alpha$-pinene is particularly interesting in this regard, because observations in the laboratory [Hatakeyama et al., 1989; Hoffmann et al., 1998] suggest that the reaction product(s) of $\alpha$-pinene and ozone have a sufficiently low vapor pressure to nucleate new particles even for very small amounts of reacted $\alpha$-pinene, provided the preexisting aerosol concentration is low. Atmospheric measurements over a northern coniferous forest [Leaitch et al., 1999] found increases in the aerosol mass load commensurate with the decay of $\alpha$ - and $\beta$-pinene during periods of high pinene concentrations, with an estimated yield of about $13 \%$.

\footnotetext{
'Naval Research Laboratory, Washington, D. C.

${ }^{2}$ Now at Computational Physics, Inc., Springfield, Virginia.

${ }^{3}$ Department of Atmospheric Sciences, University of Washington, Seattle, Washington.

${ }^{4}$ Meteorological Service of Canada, Downsview, Ontario.

${ }^{5}$ National Center for Atmospheric Research, Boulder, Colorado.

${ }^{6}$ Calspan-University of Buffalo Research Center, Buffalo, New York.
}

Copyright 2001 by the American Geophysical Union.

Paper number 2001JD900018.

0148-0227/01/2001JD900018\$09.00
There are several processes by which low-volatility organic products can partition onto existing aerosol: (1) Simple condensation on the surface of existing particles occurs when the gas-phase concentration of a low-volatility product exceeds its SVP (plus increase due to the Kelvin curvature term). (2) Condensation can also occur even when a secondary product is subsaturated with respect to itself provided the product is soluble in the existing aerosol [Odum et al., 1996]. If there is more than one condensing species, then the solubility of one condensing species with respect to the other condensing species may also be important. (3) Gaseous products can also be adsorbed onto the surface of the existing aerosol. Surface adsorption is poorly understood and difficult to represent quantitatively [Seinfeld and Pandis, $1998]$.

If the surface area of preexisting particles is low at the start of the experiment, low-volatility products can build up to the point where homogeneous nucleation occurs. The newly formed particles can then act as the preexisting aerosol for the above three processes.

For simple condensation the uptake of the supersaturated vapor depends primarily on the nature of the condensing species; i.e., its SVP. At equilibrium the concentration remaining in the gas-phase is equal to the saturation vapor pressure provided the particles have grown to the point where the Kelvin effect is negligible. For dissolution and surface adsorption the composition, aerosol volume, and surface area of the existing aerosol play a crucial role. The relationship between the measured aerosol yield and implied molar yield of condensable species will, in general, depend on which of the three processes is occurring.

Most experimental studies of gas-to-particle conversion of biogenic VOCs have examined the SOA mass increase relative to preexisting seed aerosol (usually $\left(\mathrm{NH}_{4}\right)_{2} \mathrm{SO}_{4}$ ) 
Table 1. Instrumentation

\begin{tabular}{lll}
\hline \multicolumn{1}{c}{ Measurement } & \multicolumn{1}{c}{ Manufacturer } & \multicolumn{1}{c}{ Detection Limit } \\
\hline $\mathrm{NO}_{x}$ & TECO Model 42 & $1 \mathrm{ppb}$ \\
& TECO Model 42S & $0.05 \mathrm{ppb}$ \\
$\mathrm{SO}_{2}$ & TECO Model 43S & $0.1 \mathrm{ppb}$ \\
$\mathrm{O}_{3}$ & Dasibi Model 1008 & $1 \mathrm{ppb}$ \\
$\mathrm{CN}$ concentration & TSI Model 3025A CNC & $\mathrm{r}>1.5 \mathrm{~nm}$ \\
& TSI Model 3022 CNC & $\mathrm{r}>3 \mathrm{~nm}$ \\
Aerosol size distribution & NRL DMA, 44 channels & $6 \mathrm{~nm}<\mathrm{r}<0.4 \mu \mathrm{m}$ \\
\hline
\end{tabular}

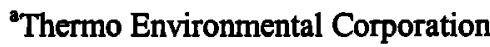

introduced prior to the start of the reaction (see references in the Discussion section). The SOA mass produced by the reaction is the difference between the mass of the preexisting particles and the aerosol mass at a later time. In the experiments to be described here, no seed particles were introduced into the system. Each experiment began with a nucleation event, followed by growth of the newly formed particles. This minimizes possible interaction of the SOA with the original seed aerosol and increases the sensitivity with which the mass increase can be measured in cases where small amounts of the reactant are used. The maximum amount of $\alpha$-pinene reacted in these experiments $(<15 \mathrm{ppb})$ was small relative to the concentrations reported in most other studies.

\section{Experiment}

\subsection{Description of the Environmental Chamber and Instrumentation}

The experiments described here were carried out in Calspan's Environmental Chamber which is $9.1 \mathrm{~m}$ in diameter and $9.1 \mathrm{~m}$ high with a total volume of $590 \mathrm{~m}^{3}$ and has a Teflon coated interior. The chamber has a large, variablespeed mixing fan and a filtration system capable of reducing the concentrations of measured gases to sub-ppb levels and particle concentrations to less than $0.1 \mathrm{~cm}^{-3}$ by overnight filtration. Filtration also included filters treated with phosphoric acid and iodized activated charcoal for removal of ammonia. Gas and particle concentrations within the chamber were measured with the instrumentation given in Table 1 with the applicable detection limits. After overnight filtering, concentrations of $\mathrm{SO}_{2}, \mathrm{NO}_{x}$, and $\mathrm{O}_{3}$ were below detectable levels. A more detailed description of the chamber, including its operation as an expansion cloud chamber and photolysis chamber, can be found in a report on characterization of the chamber [Hoppel et al., 1999].

Air removed from the chamber by sampling devices was replaced by allowing an equal amount of air back into the chamber through absolute aerosol and charcoal filters. The chamber was sealed after overnight filtering and background aerosol and gas concentrations are monitored for a minimum of 1 hour prior to the start of the experiment. Typically, the increase in background aerosol was on the order $1 \mathrm{~cm}^{-3}$ per hour, as measured with an ultrafine particle counter.

The sheath air of the differential mobility analyzer (DMA) was desiccated and the aerosol sample was removed from the chamber through a diffusion dryer. However, for the $\alpha$ pinene experiments the chamber relative humidity $(\mathrm{RH})$ was always below $50 \%$. Since the SOA products of $\alpha$-pinene are only slightly hygroscopic [Virkkula et al., 1999], the measured size is assumed to be the same as the particle size in the chamber. The DMA operated in a scanning mode which determined the aerosol size distribution every $4.5 \mathrm{~min}$.

Measurements of gas-phase $\alpha$-pinene in the chamber during the experiments were made at $15 \mathrm{~min}$ intervals using a gas chromatograph/mass spectrometer (GC/MS) in conjunction with thermal desorption. The GC employed was a Hewlett-Packard Model 5890 Series II+ in conjunction with a Discovery 2 quadrupole ion trap MS from Teledyne Electronic Technologies Inc. The thermal desorption was accomplished with a Dynatherm ACEM900 single-tube thermal desorption system. Carbotrap- 300 sorbent tubes were used for all but a few of the $\alpha$-pinene experiments that utilized Tenax-TA traps. Chamber calibration work showed no adverse effects from the usage of Carbotrap-300 tubes. Quantification for $\alpha$-pinene was based on the response relative to that of the initial injection at the test concentration. This approach assumes a linear response and a negligible $y$ intercept. "In chamber" calibration using different $\alpha$-pinene concentrations validated this assumption. Potassium iodide (KI) traps consisting of a dry coating of $\mathrm{KI}$ on glass wool were installed in the glass sampling probes to prevent degradation on the thermal desorption tubes prior to analysis due to ozone. No wall loss of $\alpha$-pinene was observed in a clean chamber over a 2-hour time period.

\subsection{Results for $\alpha$-pinene/ozone}

Plate 1 shows the temporal evolution of ozone, ultrafine particle concentration, and aerosol mass for $\alpha$-pinene/ozone oxidation experiments of October 19 and November 9, 1998, and Table 2 summarizes the conditions for each run. The $\alpha-$ pinene was introduced about $15 \mathrm{~min}$ prior to ozone, and a GC/MS measurement of the initial $\alpha$-pinene concentration was taken during this period. Ozone was then introduced over a period of about $1.5 \mathrm{~min}$, and time zero was taken to be the point where the transient ozone concentration was a maximum. The initial $\alpha$-pinene and ozone concentrations were $20 \mathrm{ppb}$ and $115 \mathrm{ppb}$, respectively, on October 19 and 16 $\mathrm{ppb}$ and $95 \mathrm{ppb}$ on November 9. The chamber's mixing fan was on during the entire experiment. After 4 to $5 \mathrm{~min}$, the concentration of ultrafine particles, as measured with the TSI $3025 \mathrm{CN}$ counter, started to increase dramatically and 

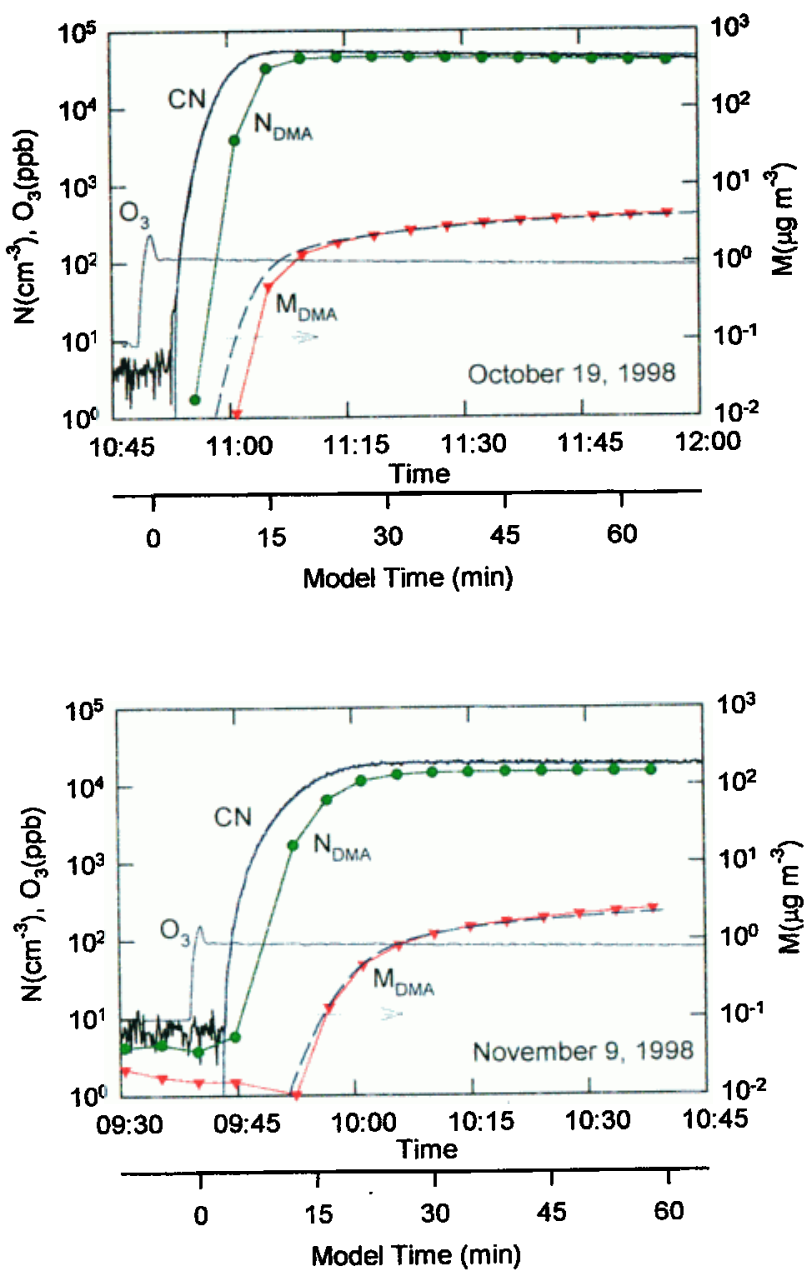

Plate 1. Temporal variations of ozone, ultrafine particle concentration, and number and mass concentrations calculated from the DMA size distribution. Aerosol mass was calculated from the volume assuming a particle density of $1 \mathrm{~g} \mathrm{~cm}^{-3}$. Symbols indicate the point at which the measurement was made. The blue lines are values of number and mass concentrations from the model simulations discussed later. Data of October 19 and November 9, 1998.
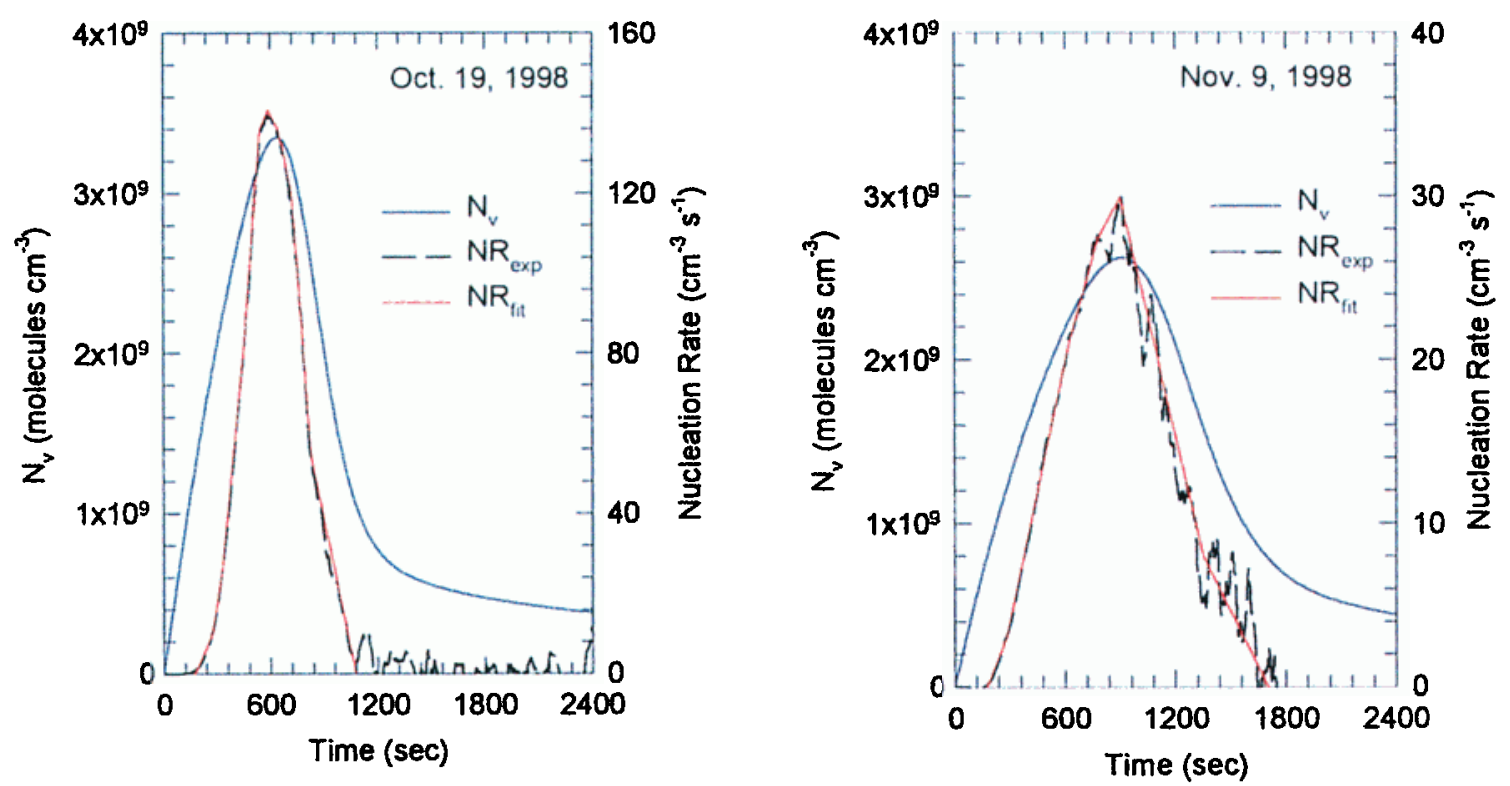

Plate 2. Measured nucleation rate $\left(\mathrm{NR}_{\text {exp }}\right)$ and predicted vapor concentration of condensing species as a function of time. $\mathrm{NR}_{\mathrm{fit}}$ is the fit to the measured nucleation rate used in the model simulations. 


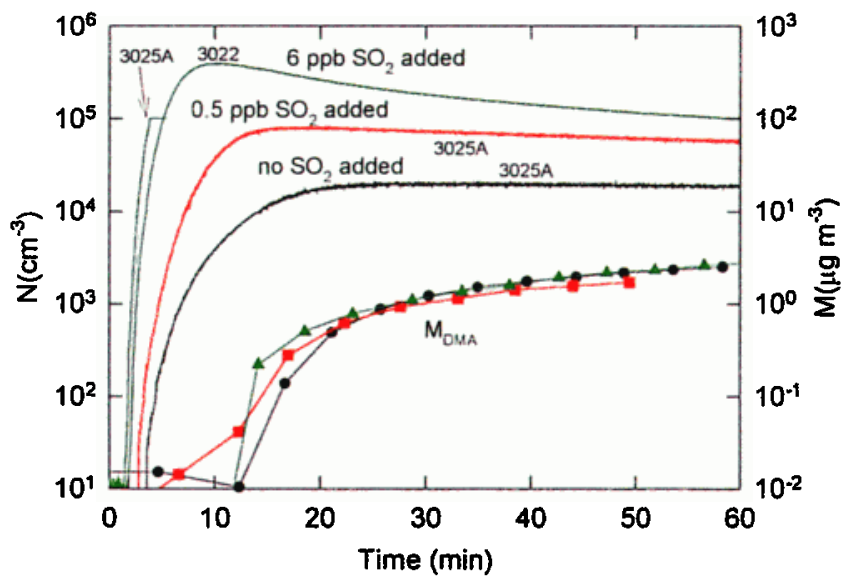

Plate 3. Comparison of results when $0.2 \mathrm{ppb}$ (November 18) and $6 \mathrm{ppb}$ (November 11) of $\mathrm{SO}_{2}$ was added to the $\alpha$ pinene/ozone system with the November 9 case when no $\mathrm{SO}_{2}$ was present.

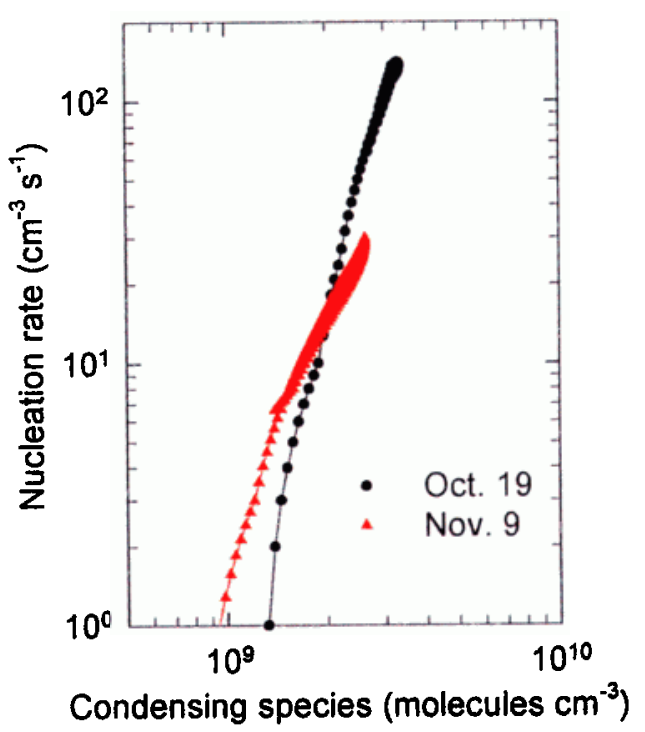

Plate 5. Nucleation rate as a function of predicted vapor concentration of condensing species for experiments of October 19 and November 9, 1998.

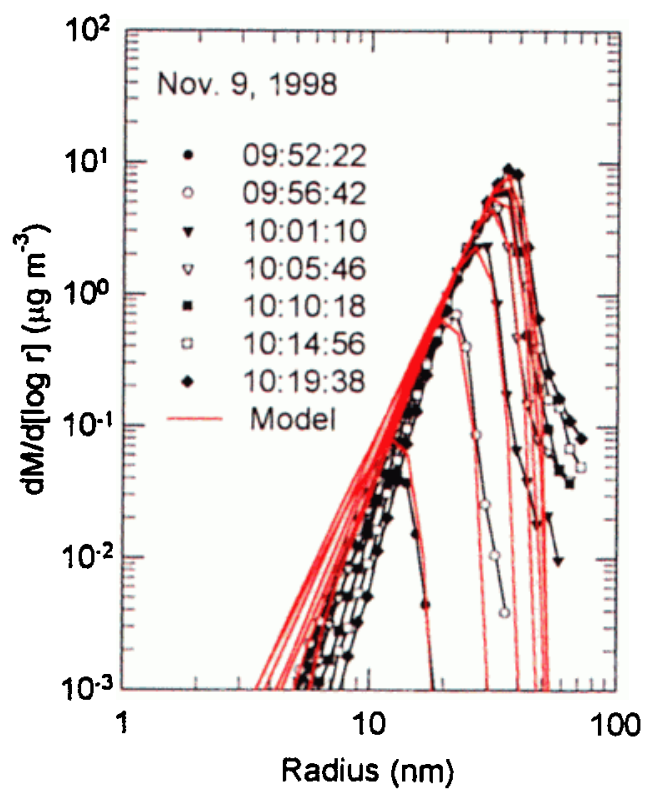

Plate 4. Comparison between the measured and model-predicted mass distributions for the experiments of October 19 and November 9, 1998. 
Table 2. Experimental Conditions

\begin{tabular}{lllllll}
\hline Date (1998) & Ozone, ppb & $\alpha$-Pinene, ppb & $\mathrm{SO}_{2}, \mathrm{ppb}$ & Temperature, C & $\mathrm{RH}, \%$ & $\begin{array}{c}\text { Maximum } \\
\mathrm{CN}, \mathrm{cm}^{-3}\end{array}$ \\
\hline Oct. 19 & 115 & 20 & none & 26 & 48 & $54 \mathrm{k}^{\mathrm{a}}$ \\
Nov. 9 & 95 & 16 & none & 25 & 29 & $20 \mathrm{k}^{\mathrm{a}}$ \\
Nov. 11 & 100 & 15 & 6.0 & 25 & 47 & $380 \mathrm{k}^{\mathrm{b}}$ \\
Nov. 18 & 110 & 15 & 0.5 & 25 & 30 & $73 \mathrm{k}^{\mathrm{b}}$ \\
\hline \multicolumn{7}{l}{${ }^{\mathrm{a}} \mathrm{CN}$ measured with TSI 3025A ultrafine CN monitor. } \\
bCN measured with TSI 3022 CN monitor.
\end{tabular}

continued to increase for a period of 15 to $20 \mathrm{~min}$ as shown in Plate 1. The maximum number of particles nucleated was $5.4 \times 10^{4} \mathrm{~cm}^{-3}$ on October 19 and $2.0 \times 10^{4} \mathrm{~cm}^{-3}$ on November 9 , consistent with a higher supersaturation being reached in the case of higher reactant levels.

The particle size distribution was measured every $4 \quad 1 / 2$ min during a 4 min voltage scan where the voltage scan was from small to large radius. The evolution of the size distribution for the November 9 experiment is shown in Figure 1 where the increasing numbers of particles is a result of nucleation of particles and the growth to larger radii is the result of condensation of SOA material. The integrated number concentration and mass concentration calculated from the measured size distribution (assuming unit density) are shown in Plate 1 by circles and inverted triangles, respectively. Since the DMA size distribution requires a 4min scan, there is some ambiguity in the time at which each point derived from the DMA data is plotted in Plate 1 . The points are plotted at the time when the maximum in the respective size distribution was measured. The time lag between the total concentration measured with the DMA and the ultrafine concentration is primarily due to the time

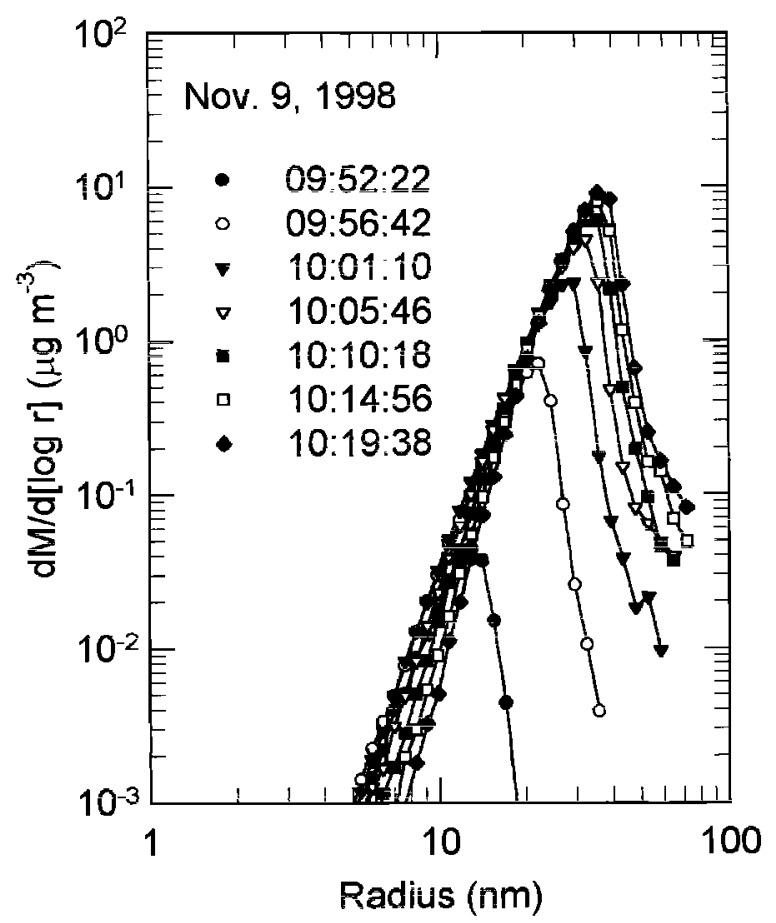

Figure 1. Evolution of the mass distribution on November 9, 1998 , as measured with the NRL 44 channel DMA. required for the particles to grow from the minimum detectable size of the ultrafine particle counter to that of the DMA. Each of the 44 channels requires about $6 \mathrm{~s}$ of measurement time. The change in the size distribution during the measurement will cause a slight broadening of the size distribution.

Because of the rapid growth of the particles, very little particle loss due to coagulation and wall deposition is expected between the time particles were formed and the time at which they were observed by the ultrafine particle counter. Under these conditions the nucleation rate as a function of time can be obtained quite accurately by taking the time derivative of the ultrafine particle concentration. A small correction for wall loss and coagulation, based on the modeling described in the next section, was applied to the TSI 3025 concentrations prior to calculating the nucleation rates. The calculated nucleation rates are discussed later and are shown by the dashed lines in Plate 2. The oscillations on the nucleation rate are caused by the TSI 3025 servo system which keeps the working fluid at a constant temperature. These oscillations in concentration are greatly enhanced in this application because (1) the particle size is at the threshold for detection and (2) taking the derivative always accentuates any variations. The red curves are fits to the calculated nucleation rate and are used in the model simulations discussed later. A discussion of the measured aerosol yields as a function of amount of $\alpha$-pinene reacted for these experiments is deferred until the next section.

\subsection{Results for $\alpha$-Pinene/SO $/ \mathrm{S}_{2} / \mathrm{Ozone}$}

During several experiments, small amounts of $\mathrm{SO}_{2}$ were introduced into the chamber between injections of $\alpha$-pinene and ozone. In Plate 3 the results of experiments on November 18 and 11 , when $0.5 \mathrm{ppb}$ and $6 \mathrm{ppb}$ of $\mathrm{SO}_{2}$ were added to the system, are compared to the November 9 result when no $\mathrm{SO}_{2}$ was present. The $\mathrm{O}_{3}$ and $\alpha$-pinene levels, as shown in Table 2 , were nearly the same for the three experiments. The mass yields of the three runs are seen to be nearly the same suggesting that the most abundant condensing product was produced by the $\alpha$-pinene/ozone reaction. However, the maximum number of particles nucleated increased dramatically, from about $2.0 \times 10^{4} \mathrm{~cm}^{-3}$ to about $4.0 \times 10^{5} \mathrm{~cm}^{-3}$ as the $\mathrm{SO}_{2}$ concentration increased to $6 \mathrm{ppb}$. Since the ultrafine counter has a dynamic range extending to only 100 $\mathrm{K} \mathrm{cm}{ }^{-3}$, we have also shown the results of the TSI-3022 for November 11 in addition to that of the TSI-3025. Because the TSI-3025 has a smaller minimum detectable size, the particles on November 11 were detected about $15 \mathrm{~s}$ earlier in the ultrafine counter than in the TSI-3022. The more rapid 
decay of the particle concentration after reaching a maximum on November 11 is the result of larger coagulative and wall losses related to the larger particle concentration on that day. The particles appeared earlier as the $\mathrm{SO}_{2}$ concentration was increased. We suspect that, when $\mathrm{SO}_{2}$ is present, the $\mathrm{OH}$ formed by the reaction of $\alpha$-pinene and ozone oxidizes the $\mathrm{SO}_{2}$ to sulfuric acid, producing seed aerosol on which the organic product of the $\alpha$-pinene/ozone reaction can interact and condense. The observed growth rate of the particles is much faster than observed in our experiments where $\mathrm{SO}_{2}$ oxidation occurs without the presence of $\alpha$-pinene. More precisely, the ratio of the number of particles formed to the rate of growth of the particles is much greater in our $\mathrm{SO}_{2} / \mathrm{H}_{2} \mathrm{SO}_{4}$ nucleation experiments than in any of the three experiments shown in Plate 3. This will be addressed further in the discussion section of this paper.

\section{Model Simulations}

By matching the results of a sectional aerosol model to observations, it is possible to determine the effective molar yield, the gas-phase concentration of the condensing species, and to estimate the effective SVP of the condensing species. The aerosol model is that described by Fitzgerald et al. [1998a, 1998b] and Gelbard et al. [1998] and was specifically modified for this application. The principal modifications were inclusion of appropriate gas-phase chemistry, loss of particles and vapor to the inside surface of the chamber, and inclusion of the Kelvin curvature term in the back pressure in the condensation term.

The model was run as a box-model (single-layer mode) using 32 size sections spanning the range from $0.6 \mathrm{~nm}$ to 85 $\mathrm{nm}$. Particle density was taken to be $1.0 \mathrm{~g} \mathrm{~cm}^{-3}$. Aerosol processes determining the evolution of the particle size distribution are condensation, nucleation, coagulation, and wall deposition. Water absorption on the particles is assumed to be negligible. This is justified by the recent study of Virkkula et al. [1999] which showed that the aerosol formed from the oxidation of $\alpha$-pinene by ozone was only slightly hygroscopic, with $d_{\text {wet }} / d_{\text {dry }}=1.07$ at $84 \% \mathrm{RH}$. The chamber relative humidity during our experiments ranged from $30 \%$ to $50 \%$ and the DMA is operated at about $8 \% \mathrm{RH}$. Thus all calculations are done in terms of dry particle size and particles are assumed to have the same size in the chamber and the DMA.

Aerosol wall loss is described by $d N_{p, i} / d t=-\lambda_{p, l} N_{p, i}$, where $N_{p, i}$ is the particle concentration in section $i, \lambda_{p, i}=D_{i} / \delta_{i}(S / V)$ is the particle decay constant, $S / V=0.67 \mathrm{~m}^{-1}$ is the surface-tovolume ratio of the chamber, $D_{i}$ is the Brownian diffusion coefficient for particles in section $i$, and $\delta_{i}$ is the sizedependent diffusion boundary layer thickness. From solutions to the diffusion equation for the variation of particle concentration in the vicinity of a wall, we might expect that $\delta_{\text {, }}$ is proportional to $1 / r_{p, r}$ for particle radius $r_{p}<50 \mathrm{~nm}$. The constant of proportionality was estimated by fitting this expression to values of $\delta$ for particles in the size range of 6 $\mathrm{nm}$ to $20 \mathrm{~nm}$ that were determined by measuring the decay in particle concentrations in the chamber over a $45-\mathrm{min}$ period. In these decay experiments, condensation was not occurring (there was no generation of condensable vapor), and coagulation was minimized by reducing the total particle concentration below $10,000 \mathrm{~cm}^{-3}$. The resulting expression is $\dot{\delta}_{i}=0.9 / r_{p, i}$, where $\delta$ and $r_{p}$ are in microns, and is applied over the entire size range of interest.

In the model, nucleated particles are introduced with time at a rate determined by the observed nucleation rate, shown by the red line in Plate 2. Nucleated particles can be introduced at any size greater than their critical size. If the embryos are introduced at a radius less than the critical size, their growth is prohibited by the fact that the equilibrium vapor pressure at the particle surface will be greater than the ambient vapor pressure. The data from the Model $3025 \mathrm{CN}$ counter, which has a minimum detectable radius of $1.5 \mathrm{~nm}$, together with the data from the Model 3022 which has a larger minimum detectable size, indicate the particles are certainly growing at a radius of about $2.5 \mathrm{~nm}$. (They may be growing at a smaller size below our detection limit.) In the model the particles are introduced in the section having a mean radius of $2.6 \mathrm{~nm}$ and are assumed to begin growing by condensation immediately.

It is known that the reaction of $\alpha$-pinene with ozone produces $\mathrm{OH}$, which in turn will react with $\alpha$-pinene. If it is assumed that the oxidation of $\alpha$-pinene by ozone and secondary $\mathrm{OH}$ produce the same condensing species with the same molar yield $\gamma$, then the relevant diagnostic equations for the concentrations of the condensing vapor $\left(N_{v}\right)$, ozone, and $\alpha$-pinene (denoted by $\mathrm{HC}$ ) in molecules $\mathrm{cm}^{-3}$ are

$$
\begin{gathered}
\frac{d N_{v}}{d t}=\gamma\left[k_{\mathrm{O}_{3}}\left\{\mathrm{O}_{3}\right\}\{\mathrm{HC}\}+k_{\mathrm{OH}}\{\mathrm{OH}\}\{\mathrm{HC}\}\right] \\
-\lambda_{v} N_{v}-4 \pi \sum_{i} D^{\prime}\left(r_{i}\right) r_{i}\left[N_{v}-N_{v}^{s v p} \exp \left(\frac{A}{r_{i}}\right)\right] Z_{i} \\
\frac{d\left\{\mathrm{O}_{3}\right\}}{d t}=-k_{\mathrm{O}_{3}}\left\{\mathrm{O}_{3}\right\}\{\mathrm{HC}\}-\lambda_{\mathrm{O}_{3}}\left\{\mathrm{O}_{3}\right\} \\
\frac{d\{\mathrm{HC}\}}{d t}=-k_{\mathrm{O}_{3}}\left\{\mathrm{O}_{3}\right\}\{\mathrm{HC}\}-k_{\mathrm{OH}}\{\mathrm{OH}\}\{\mathrm{HC}\}-\lambda_{\mathrm{HC}}\{\mathrm{HC}\}
\end{gathered}
$$

where $k_{\mathrm{O} 3}$ and $k_{\mathrm{OH}}$ are the rate constants for the reaction of $\mathrm{O}_{3}$ and $\mathrm{OH}$ with $\alpha$-pinene, respectively; $\lambda_{v}, \lambda_{\mathrm{O} 3}$, and $\lambda_{\mathrm{HC}}$ are the wall loss decay constants for the vapors; $Z_{i}$ is the number concentration of particles in section $i:$ and $N^{\text {SVP }}$ is the saturation vapor concentration of the condensing species. The values of $k_{\mathrm{O} 3}$ and $k_{\mathrm{OH}}$ are $8.66 \times 10^{-17} \mathrm{~cm}^{3}$ molecule $\mathrm{s}^{-1}$ and $5.37 \times 10^{-11} \mathrm{~cm}^{3}$ molecules $\mathrm{s}^{-1}$ at $298 \mathrm{~K}$ [Atkinson, 1994]. In the Kelvin curvature term in equation (1), $A=2 \sigma M_{v} / \rho R^{*} T$ where $M_{v}$ is the molecular weight of the condensing species; $\sigma$ and $\rho$ are the surface tension and density of the condensate; $R^{*}$ is the universal gas constant, and $T$ is temperature. Since the nature of the condensing species is unknown, we use an estimated value of the product $\sigma M_{v} / \rho$. The $M_{v}$ of 14 products of the $\alpha$-pinene ozone reaction identified by $Y u$ et al. [1999] ranged from 140 to $200 \mathrm{AMU}$ with the most frequent value around 184 AMU. The density and surface tension of these products are, for the most part, unknown. Scanning the surface tension and densities of organic acids listed in the CRC Handbook would suggest that a surface tension in the range of 20 to 40 dyne cm $\mathrm{cm}^{-1}$ and density of $1.0 \mathrm{~g} \mathrm{~cm}^{-3}$ would not be unreasonable. We here take values of $180 \mathrm{AMU}, 27$ dyne $\mathrm{cm}^{-1}$, and $1.0 \mathrm{~g} \mathrm{~cm}^{-3}$ for the values of molecular weight, surface tension, and density of the unknown SOA product(s). The resulting value of $\mathrm{A}$ is approximately $4.0 \times 10^{-7} \mathrm{~cm}$ at the chamber temperature of $298 \mathrm{~K}$. 
The quantity $D^{\prime}\left(r_{l}\right)$ is the modified vapor diffusion coefficient for a particle of radius $r_{\imath}$ [Fitzgerald et al., 1998a]. For the particle size range of interest the kinetic theory growth regime applies, and $D\left(r_{i}\right)=\alpha r_{i} v / 4$, where $\alpha$ is the condensation coefficient (assumed to be unity) and $v=1.46 \mathrm{x}$ $10^{4}\left(\mathrm{~T} / \mathrm{M}_{\mathrm{v}}\right)^{1 / 2} \mathrm{~cm} \mathrm{~s}^{-1}$ is the average thermal velocity of the condensing vapor molecules.

The values of $\lambda_{\mathrm{O} 3}$ and $\lambda_{\mathrm{HC}}$ were determined by wall loss measurements in the chamber [Hoppel et al., 1999] and are $5 \times 10^{-5} \mathrm{~s}^{-1}$ and 0 , respectively. No wall loss of $\alpha$-pinene was observed over a 2-hour period within experimental accuracy. The wall loss constant of the condensing species could not be measured, and its value was selected to fine tune agreement between model results and observations, as discussed below.

Since we cannot accurately quantify the sinks of $\mathrm{OH}$ due to its reaction with other products of the oxidation of $\alpha$-pinene by $\mathrm{O}_{3}$, we cannot calculate the $\mathrm{OH}$ concentration by assuming a steady state balance between the sources and sinks of $\mathrm{OH}$. Instead, the concentration of $\mathrm{OH}$ was estimated from measurements of the decay of $\alpha$-pinene in the presence of $\mathrm{O}_{3}$. Four separate determinations of $\alpha$-pinene decay were made. In each case, three or four measurements of $\alpha$-pinene were made at 5-10 min intervals over a period of about $60 \mathrm{~min}$, and an exponential decay curve was fit to the data points. For the initial $\mathrm{O}_{3}$ concentration of $110 \mathrm{ppb}, \alpha$-pinene is expected to decay exponentially with a decay constant of about 0.0124 $\min ^{-1}$ if it is oxidized by $\mathrm{O}_{3}$ only. The observed decay constants ranged from $0.0132 \mathrm{~min}^{-1}$ to $0.0156 \mathrm{~min}^{-1}$, the average value being $0.0143 \mathrm{~min}^{-1}$. If we attribute the higher decay rate of $\alpha$-pinene to additional oxidation by secondary $\mathrm{OH}$, then the observed average decay rate implies an $\mathrm{OH}$ concentration of about $7 \times 10^{5}$ molecules $\mathrm{cm}^{-3}$. It is important to emphasize that this is just an effective $\mathrm{OH}$ concentration required to make the predicted $\alpha$-pinene decay equal the measured decay, not necessarily the actual $\mathrm{OH}$ concentration.

Mass conservation of the condensing species provides a further constraint and results in the following expression for its molar yield $\gamma$

$$
\gamma=\frac{1}{\Delta\{\mathrm{HC}\}}\left[\frac{V_{\mathrm{aer}} \rho N_{\mathrm{Av}}}{M_{v}}+N_{v}+L_{\mathrm{aer}}+L_{v}\right],
$$

where $\Delta\{\mathrm{HC}\}$ is the calculated amount of $\alpha$-pinene reacted (in molecules $\mathrm{cm}^{-3}$ ) and the four terms in brackets are, respectively, the concentrations of the condensing species in the aerosol and vapor phase, and the concentration of condensing species lost to the walls due to aerosol $\left(L_{\text {aer }}\right)$ and vapor $\left(L_{v}\right)$ deposition. All terms are evaluated at the same point in time, and concentrations are expressed in molecules $\mathrm{cm}^{-3}$. In the expression for aerosol concentration, $V_{\text {aer }}$ is the measured aerosol volume concentration $\left(\mathrm{cm}^{3} / \mathrm{cm}^{3}\right), \rho$ is particle density, and $N_{\mathrm{Av}}$ is Avogadro's number. It is preferable to do the mass balance calculation at a sufficiently long time so that a high percentage of the condensing species produced is in the aerosol phase. We have chosen a mass balance time of $30 \mathrm{~min}$.

Equations (1)-(4), together with the sectional aerosol equations, were used to simulate the evolution of the aerosol size (mass) distribution and condensing species vapor concentration for the $\alpha$-pinene and ozone oxidation experiments of October 19 and November 9, 1998. By matching the model predictions with observations we can obtain estimates of $\gamma$, the upper limit to the value $N_{v}{ }^{\mathrm{SVP}}$, and the relationship between the nucleation rate and the condensing species vapor concentration.

There are two criteria in the model which determine the SVP of the condensing species: (1) the modeled growth must match the observed growth, and (2) the value of $N_{v}^{\text {SVP }}$ must be low enough so that the product $N_{v}{ }^{\mathrm{SVP}} \exp \left(A / r_{c}\right)$ is less than the predicted concentration when nucleation commences (defined as a nucleation rate of $\left.1 \mathrm{~cm}^{-3} \mathrm{~s}^{-1}\right)$. Here $r_{c}(=2.6 \mathrm{~nm})$ is the minimum radius at which we are certain that growth is occurring when nucleation commences and is therefore an upper limit to the critical embryo size. If this latter condition is not met, then nucleated particles will not grow immediately, and there will not be agreement between the predicted and measured cumulative particle concentrations as a function of time and between the predicted and measured size distributions. It turns out that the second criteria is more stringent than the first and is the one used to determine the value of SVP stated here. We find that $N_{v}{ }^{\text {SVP }}<2.7 \times 10^{8}$ molecules $\mathrm{cm}^{-3}(=0.011 \mathrm{ppb})$ for the experiment of October 19,1998 and $N_{v}{ }^{\text {SVP }}<2.0 \times 10^{8}$ molecules $\mathrm{cm}^{-3}(=0.008 \mathrm{ppb})$ for November 9,1998 . We view these values as upper limits of the SVP since we can find equally good results for lower values of the SVP.

The values of the molecular weight $M_{v}$ and wall loss decay constant $\lambda_{\nu}$ for the condensing vapor were selected to fine tune the agreement between the time of the peak nucleation rate and the time of the maximum vapor concentration. An increase in $\lambda_{v}$ and a decrease in $M_{\nu}$ decreases the time at which the vapor peaks. In these simulations we use $M_{v}=180$ and $\lambda_{v}=7 \times 10^{-4} \mathrm{~s}^{-1}$. With this combination of values there is a just a 10-s difference between the nucleation peaks for November 9 and a 40-s difference on October 19 (Plate 2). This value of $\lambda_{v}$ s 2.7 times the measured value for $\mathrm{SO}_{2}$ and is not unreasonable for a low-volatility species.

The values of the vapor concentration and the aerosol and vapor lost to the chamber walls needed to calculate the molar yield from equation (4) were those predicted by the model. With $\gamma$ evaluated in this way, the model-predicted aerosol mass concentration in the chamber at mass balance time will be exactly equal to the observed mass concentration. The computed values of molar yield for October 19 and November 9 are 0.056 and 0.052 , respectively.

Model-predicted aerosol mass concentrations and particle number concentrations as a function of time are compared with measured values in Plate 1 . It is seen that the increase in organic aerosol mass over the 1-hour period of observation can be accounted for quite well by condensation of an "effective" single low-volatility reaction product having a molar yield of about 5 to $6 \%$. The relatively small difference between the predicted and measured aerosol mass before and after the time $(30 \mathrm{~min})$ at which mass conservation was calculated could be due to a number of factors including departure of the actual temporal variation of the aerosol and vapor wall loss from that predicted by the model, and small errors in the measurement of particle volume. Also, we cannot rule out the possibility that there may be a small contribution from condensation of additional, more volatile, products which form a solution with the primary product(s).

Plate 2 shows the measured nucleation rate and predicted vapor concentration of the condensing species as a function of time. It should be particularly noted that the peak nucleation rate and peak vapor concentration occur at essentially the 
same time. In the following section it is argued that even if the $\alpha$-pinene oxidation product responsible for nucleation is different from the condensing species, it should peak at the same time as the condensing species.

Plate 4 presents a comparison between the measured and predicted mass distributions for both experiments. It is seen that condensation of a single low-volatility reaction product describes the observed evolution of the particle size distribution quite well.

Plate 5 is a plot of the nucleation rate as a function of condensing species concentration. One branch of the curve is for increasing concentrations of $N_{v}$, and the other is for decreasing $N_{v}$. A detailed comparison of the observed slope of the nucleation curves with the slope predicted by nucleation theory is also given in the following section.

Plate 6 shows the measured and predicted aerosol mass yields as a function of the amount of $\alpha$-pinene that has reacted. The aerosol yield is defined as the ratio of the aerosol mass concentration to the mass concentration of $\alpha$ pinene reacted at a given time. For the case where the SOA results from condensation of a single vapor, the observed aerosol yield is given by

$$
Y_{\mathrm{obs}}=\left\{\gamma \frac{M_{v}}{M_{\mathrm{HC}}} \Delta[\mathrm{HC}]-\zeta_{\mathrm{aer}}-\zeta_{v}-\rho_{v}\right\} / \Delta[\mathrm{HC}],
$$

where $\rho_{\nu}$ is the condensing vapor mass concentration ( $\mu \mathrm{g}$ $\left.\mathrm{m}^{-3}\right), \Delta[\mathrm{HC}]$ is the mass concentration $\left(\mu \mathrm{g} \mathrm{m}^{-3}\right)$ of $\alpha$-pinene reacted up to a given time, and $\zeta_{\mathrm{aer}}$ and $\zeta_{v}$ are the mass concentrations of aerosol and vapor lost to the walls. In the absence of wall losses, equation (5) gives the mass yield as

$$
Y=\gamma \frac{M_{\nu}}{M_{H C}}-\frac{\rho_{\nu}}{\Delta[H C]}
$$

The mass yield is zero prior to the start of nucleation, when all the condensing product is in the vapor phase. After nucleation begins, the yield increases rapidly as the supersaturated vapor condenses. After a sufficiently long time, $\rho_{\mathrm{v}}$ approaches the saturation vapor density $\rho_{\text {sat }}, \Delta[\mathrm{HC}]$ approaches the initial concentration of $\alpha$-pinene as the reaction goes to completion, and the yield approaches the value $\gamma\left(M_{v} / M_{\mathrm{HC}}\right)-\rho_{\mathrm{sat}} /[\mathrm{HC}]_{\text {init }}$. If $\rho_{\text {sat }}$ is very small compared to $[\mathrm{HC}]_{\text {int, }}$, as in this case, the yield attains a maximum value equal to the stoichiometric mass yield $\gamma\left(M_{v} / M_{\mathrm{HC}}\right)$ [see, e.g., Seinfeld and Pandis, 1998]. Since the simulations use $M_{\nu}=180$ and the molecular weight of $\alpha$-pinene is 136 , the stoichiometric mass yields are 0.074 and 0.069 for October 19 and November 9, respectively. Because of wall losses, the observed and predicted mass yield curves level off at a value lower than the actual stoichiometric mass yields, shown in Plate 6. While the measured yield curves behave much as would be expected assuming a single condensing species, it may well be that there is more than one condensing species, in which case the yield is the sum of the individual yields, and the single component must be viewed as an "effective" single component which exhibits a SVP and yield as determined above. Since we can fit the data assuming a single component, there is no advantage to assuming additional components. In prior studies where the yield of a number of VOCs have been measured, it is clear that a two-component absorption model is required to adequately fit the data for most of the VOCs studied [Odum et al., 1996]. As discussed later, for the $\alpha$-pinene/ozone system, it is not clear that a twocomponent absorption model is needed to fit the yield curve within the accuracy of the data.

\section{Discussion}

\subsection{Yields and Vapor Pressures of SOA from $\alpha$-Pinene Oxidation by Ozone}

It is difficult to make a meaningful comparison of the aerosol yields and SVP of the condensing species found here and those found in prior studies because of the differences in experimental conditions and procedures. For the most part, the values of yield and SVP reported here are substantially smaller than those found in the prior studies. The most conspicuous experimental differences in the various studies of $\alpha$-pinene oxidation by ozone relate to (1) use of preexisting seed aerosol, (2) use of $\mathrm{OH}$ scavenger, (3) concentration of reactants, and (4) the possible role of secondary reactions producing condensable products on a timescale longer than that observed in a given experiment.

1. In the experiments described here, no preexisting seed particles were injected into the chamber. One of our goals was to look at nucleation of aerosols in the $\alpha$-pinene/ozone system. Preexisting aerosol provides a sink for the condensing product, lowering the gas-phase concentration of the product and suppressing nucleation of new particles.

2. No $\mathrm{OH}$ scavenger was introduced into the chamber. In addition to the $\alpha$-pinene/ozone reaction, there was undoubtedly $\mathrm{OH}$ produced by the $\alpha$-pinene/ozone reaction which then was available to react further with $\alpha$-pinene and other products of the $\alpha$-pinene/ozone reaction. We believe that this is closer to what happens in the real atmosphere.

3. As discussed earlier, the secondary aerosol yield depends on the amount of HC reacted. No SOA is formed until the concentration of the condensing species exceeds its SVP. If sufficient $\mathrm{HC}$ is reacted, the SOA yield will increase until the amount of the product in the vapor is small compared to the amount condensed. Even for the case of absorption of a soluble species in the existing aerosol, the amount dissolved in solution will depend on the SVP of the absorbed species via the absorption coefficient. The more HC reacted the larger is the potential for products with a higher SVP to contribute substantially to the SOA. In our experiments the amount of $\alpha$-pinene was low relative to most other experiments. The total amount of $\alpha$-pinene reacted was about $15 \mathrm{ppb}$ and was reacted over a period of about 1 hour. The mass yield as a function of reacted $\alpha$-pinene can be used to infer the molar yield (stoichiometric coefficient) of the various SOA products. While the molar yield is not dependent on the amount of $\alpha$-pinene reacted, higher vapor pressure products start to contribute to the SOA as the amount of reacted $\alpha$-pinene increases, making it difficult to get a molar yield applicable to the small amounts of $\alpha$-pinene reacted in the atmosphere.

4. There is evidence that additional SOA is formed by secondary reactions which occur on a timescale longer than the initial oxidation of $\alpha$-pinene by ozone [Hatakeyama et al., 1989]. When the concentration of reactants is very small, these secondary reactions may occur at a time beyond our observational period.

Our experiments are most closely related to those of Hatakeyama et al. [1989], who carried out total aerosol yield 


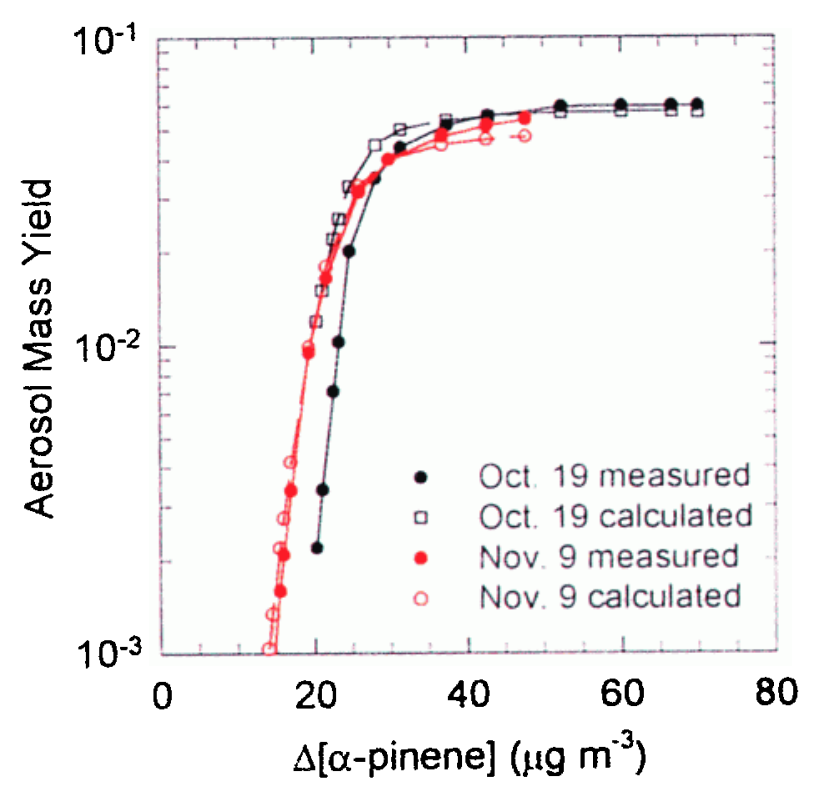

Plate 6. Measured and predicted aerosol mass yield as a function of the amount of $\alpha$-pinene reacted for the experiment of October 19 and November $9,1998$.

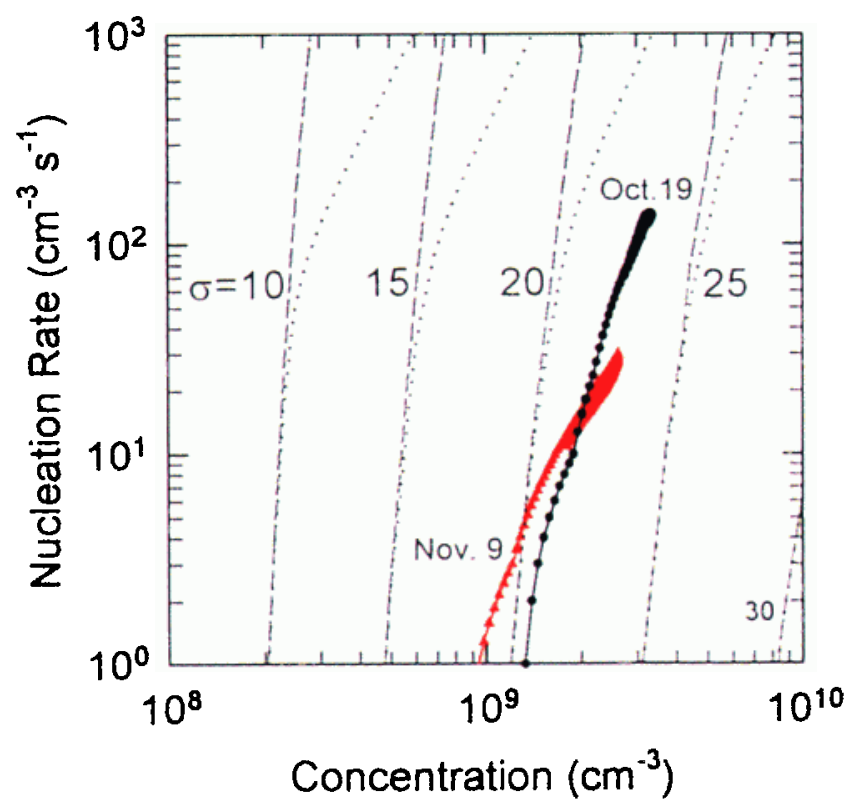

Plate 7. Nucleation rate for surface tensions of $10.15,20,25$, and 30 dyne $\mathrm{cm}^{-1}$ as calculated from equation (7) are given as dashed lines. The dotted lines are for the case when $\beta_{1}$ is $10^{-6}$ times the collision rate. The observed nucleation curves are the same as those in Plate 8.

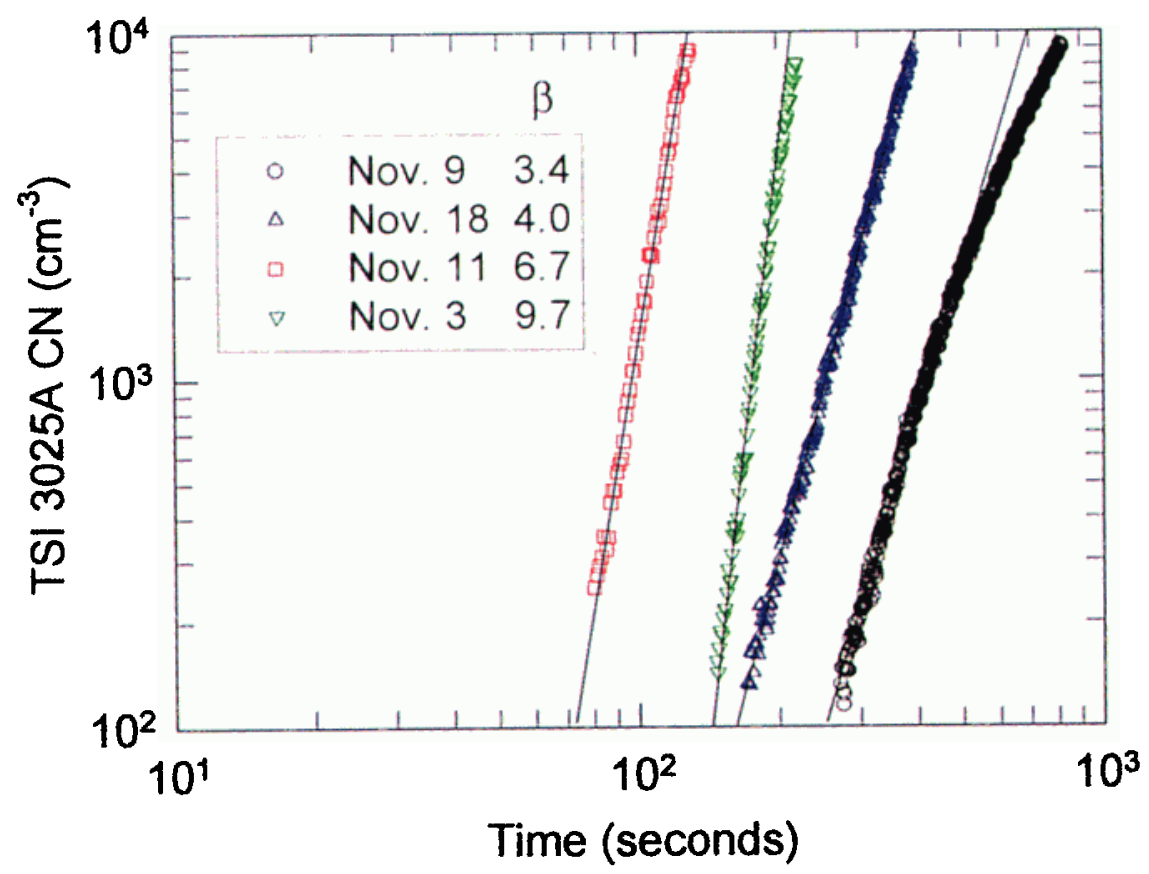

Plate 8. Plots of total particle concentration versus time for cases when $0,0.5$, and $6 \mathrm{ppb}$ of $\mathrm{SO}_{2}$ are present in the $\alpha$-pinene/ozone system (November 9,18 , and 11 , respectively) and the case of $\mathrm{H}_{2} \mathrm{SO}_{4}$ nucleation from $\mathrm{SO}_{2}$ with no $\alpha$-pinene present (November 3). 
experiments in a $4 \mathrm{~m}^{3}$ glass-lined chamber using $16 \mathrm{ppb}$ of $\alpha-$ pinene, no seed nuclei, and no $\mathrm{OH}$ scavenger. However, Hatakeyama et al. [1989] used an ozone concentration of about $800 \mathrm{ppb}$ that is 8 times the concentration used in our experiments. Because of the faster reaction, the initial supersaturation is greater in their experiment than in ours. The larger supersaturation resulted in a nucleation event, where about $130 \times 10^{3} \mathrm{~cm}^{-3}$ were formed, compared to about $50 \times 10^{3}$ and $20 \times 10^{3} \mathrm{~cm}^{-3}$ in our experiments. The results of both studies are consistent with a nucleating species that have a SVP of the same order of magnitude. Hatakeyama et al. [1989] found a mass yield of $30 \%$ (assuming unit density) which they converted to a carbon yield of $18.9 \%$ using a previously determined factor between volume and aerosol organic carbon. This yield is 5 times greater than the mass (volume) yield determined in our experiments. We have no explanation for this large difference in yield between the two experiments. However, we would like to point out that Hatakeyama et al. [1989] used an Electrical Aerosol Analyzer (EAA) for their measurement of the size distribution. Having used EAAs extensively 2 decades ago and having compared EAA data with the more accurate Differential Mobility Analyzer (DMA) used in this experiment, we would not be surprised if the differences were largely the result of instrumental inaccuracies in aerosol volume determined from the EAA data.

Hoffmann et al. [1997] examined organic aerosol formation from the oxidation of a number of biogenic hydrocarbons including $\alpha$-pinene. In those experiments, ammonium sulfate seed aerosol was used so that SOA products condensed (or possibly were absorbed) onto the preexisting aerosol. No $\mathrm{OH}$ scavenger was introduced. For dark $\alpha$-pinene/ozone reactions, aerosol mass yields of 13.7 to $23 \%$ were found, where the amount of reacted $\alpha$-pinene ranged from $38 \mathrm{ppb}$ to $154 \mathrm{ppb}$. By fitting the SOA yield data to a two-product equilibrium absorption model [Odum et al., 1996], Hoffmann et al. [1997] found that the yield curve could be fit by one product with absorption coefficient greater than about $0.2 \mathrm{~m}^{3} \mu \mathrm{g}^{-1}$, which corresponds roughly to a SVP lower than several ppb, and a second product with an absorption coefficient about 40 times smaller (SVP about 40 times larger). The implied molar yields of the two products were $12 \%$ and $19 \%$. To compare the Hoffmann et al. [1997] yields to our observed yields, their yield curve must be extrapolated down to about $10 \mathrm{ppb}$ of reacted $\alpha$-pinene at which point the amount of the higher-volatility product is negligible. Nevertheless, the molar yield of $12 \%$ found by Hoffmann et al. for the lower-volatility product is about twice the molar yield found in our experiments. How much SOA could be due to absorption on the preexisting ammonium sulfate aerosol, not present in our experiment, is unknown. Hoffmann et al. [1997] found that the fit to the data was relatively insensitive to the vapor pressure of the lowvolatility product provided it was less than several $\mathrm{ppb}$. The implied SVP of the low-volatility product in our experiments was below $0.01 \mathrm{ppb}$. (In cases where the experiments are fit to the two-product absorption model, it is the absorption coefficients that are determined, not the SVP of the two products. The saturation vapor pressure is inversely related to the absorption coefficient. Where we give values of SVP estimated from the absorption coefficient, we have used Figure 10 of $Y u$ et al. [1999].)
Two recent papers, Griffin et al. [1999] and $Y u$ et al. [1999], have reported SOA yields from oxidation of biogenic hydrocarbons. Each of these studies, unlike ours, utilized ammonium sulfate seed aerosol and an $\mathrm{OH}$ inhibitor, and therefore the results may not be comparable to the results given in this paper. Griffin et al. [1999] fit their SOA yield data to the two-product absorption model and suggested two products with similar molar yield (12.5\% and 10.2\%) and similar vapor pressures (absorption coefficients of 0.088 and $0.078 \mathrm{~m}^{3} \mu \mathrm{g}^{-1}$ or SVP of the order of $10 \mathrm{ppb}$ ). Yu et al. [1999], fitting their data to the same two-product absorption model, found two products having molar yields of $26 \%$ and $6.2 \%$ and vapor pressures of the order of $100 \mathrm{ppb}$ and $10^{4} \mathrm{ppb}$ (absorption coefficients of 0.03 and $0.0028 \mathrm{~m}^{3} \mathrm{\mu g}^{-1}$ ).

In both the Hatakeyama et al. [1989] and Hoffmann et al. [1997] results, where no $\mathrm{OH}$ inhibitor was used, a lowvolatility product can be implied from the data. In the Hatakeyama et al. [1989] experiment the large homogeneous nucleation event requires a low vapor pressure product to be formed in the $\alpha$-pinene/ozone reaction. While the yield data obtained by Hoffmann et al. [1997] was fit (Figure 2 of Hoffmann et al. [1997]) using an absorption coefficient of 0.2 $\mathrm{m}^{3} \mu \mathrm{g}^{-1}$ (SVP of a few $\mathrm{ppb}$ ) for the low-volatility product, it is clear that the data could be fit equally well if the lowvolatility product had a volatility much lower than that stated in the paper. The insensitivity of the fit to vapor pressure, provided it was lower than the value chosen, was pointed out by Hoffmann et al. [1997]. Thus the existence of very low vapor pressure product(s), as found in our experiment, is not very surprising.

\subsection{Product Identification}

A great deal of effort has been expended in the difficult task of identifying the SOA products produced by oxidation of biogenic hydrocarbons [see, e.g., Yu et al., 1999; Jang and Kamens, 1999; Christoffersen et al., 1998; and references therein]. Many products from the $\alpha$-pinene/ozone reaction system have been identified. The following are believed to contribute to the SOA provided sufficient $\alpha$-pinene is reacted: cis-pinic acid, pinonic acid, norpinonic acid, pinonaldehyde, and norpinonaldehyde (for a more comprehensive list, see references above). The estimated SVP's of the above listed products [Yu et al., 1999] are not sufficiently low (all greater than $10 \mathrm{ppb}$, some greater than $100 \mathrm{ppb}$, at room temperature) to account for the nucleation observed in this study or that of Hatakeyama et al. [1989], or the yield curve of Hoffmann et al. [1997]. However, Christoffersen et al. [1998] estimates the SVP of cis-pinic acid to be $0.0015 \mathrm{ppb}$; whereas, Yu et al. [1999] estimate a value of $67 \mathrm{ppb}$ for cis-pinic acid. These differences illustrate the huge uncertainties that exist in the estimated SVP of these organic products.

The implied existence of reaction product(s) in the $\alpha$ pinene/ozone reaction with SVP low enough to initiate homogeneous nucleation led Hoffmann et al. [1998] to look for an analytical method to detect less volatile products. Using both an off-line technique and an on-line chemical ionization mass spectrometry technique, Hoffmann et al. [1998] was able to detect, not only the difunctional carboxylic acids, but also stable binary diacid adducts, such as, a stable dimer of cis-pinic and norpinic acid. The experiments also indicated that the stable dimer had a lower vapor pressure 
than either of the diacids. They furthermore speculate that these adducts might play a key role in nucleation of new particles by a mechanism not describable by classical nucleation theory.

In this work we have not attempted to identify the chemical composition of SOA formed from the $\alpha$-pinene/ozone reaction, but rather to determine some physical parameters such as the molar yield, saturation vapor pressure, and nucleation potential of the least volatile product(s) which can be used to characterize nucleation and SOA formation from $\alpha$-pinene in the atmosphere. Since adducts, unlike clusters, are stable, the adduct concentration would be expected to build up as long as there were monomers to react; thus the adduct(s) may well play a role in the nucleation and growth observed in our experiments.

\subsection{Nucleation}

In the modeling section it was shown that the condensing species (or the single-component surrogate, if there is more than one condensing species) has a SVP of about $0.01 \mathrm{ppb}$ (or lower), with a calculated concentration which peaks at the same time as the nucleation rate (see Plate 2 ). The very low vapor pressure of the condensing species coupled with the maximum vapor concentration $\left(\sim 3 \times 10^{9}\right.$ molecules $\mathrm{cm}^{-3}$, Plate 2) required to drive the observed condensation gives a maximum supersaturation of over 15 (assuming the upper bound of the SVP). This suggests that the condensing species may also have a low enough SVP to be the nucleating species. It could be argued that there may be a separate nucleating species present at a lower concentration than the dominant condensing species; or even that there is heteromolecular nucleation and condensation taking place. In the latter two cases the single-species representation would be viewed as an "effective" one-species representation. If there is more than one species, and if their production rates can be represented by different stoichiometric coefficients of the $\alpha$-pinene/ozone reaction, and further, if the sink is the result of condensation on the aerosol surface area, then the concentration of each species will scale according to the stoichiometric coefficient; i.e., the concentration of each species contributing to the condensation will peak at the same point in time. The nucleation rate as a function of nucleating species would then have the same slope as that shown in Plate 5, where the abscissa will scale according to the stoichiometric coefficients. At long times the scaling will break down due to different SVPs of the species.

The slopes of the observed nucleation curves in Plate 7 (also Plate 5) are smaller (log slope of about 3 to 4 ) than would be expected from classical nucleation theory. In the classical theory the nucleation rate is most affected by the surface tension of the critical embryo. The heavy dashed lines in Plate 7 show a comparison of nucleation rate versus concentration for a range of surface tensions (10 to 30 dyne $\mathrm{cm}^{-1}$ ), assuming a SVP of $0.0025 \mathrm{ppb}$ (one quarter of the upper bound determined earlier) and molecular weight of 186 . It is important to note that we did not use either of the standard forms of the classical equation (unconstrained or constrained, as, for example, equations (10.47) and (10.74) of Seinfeld and Pandis [1998]) to generate Plate 7. These standard equations require that the number of molecules in the critical embryo be much greater than one. In the standard form of the nucleation equation the log slope is equal $i^{*+1}$ or $i^{*}+2$ where $i^{*}$ is the number of molecules in the critical embryo, depending on whether the self-consistency correction is applied [see, e.g., Viisanen and Strey, 1994]. Since the observed log slope is about 3 to 4 , the assumptions leading to the standard form of the equations cannot possibly hold. The nucleation rates shown in Plate 7 were generated from an equation equivalent to that of equation 10.29 of Seinfeld and Pandis [1998]

$$
J=N_{1}\left(\sum_{i=1}^{t_{c}} \frac{1}{\beta_{i} S^{i} \exp \left(E_{i}\right)}\right)^{-1},
$$

where $\beta_{i}$ is the collision rate of monomers of concentration $N_{l}$, with clusters composed of $i$ monomers, $S$ is the saturation ratio $\left(N_{f} / N_{\text {svp }}\right), E_{t}$ is an exponent containing the surface tension and $i_{c}$ denotes the number of monomers in the critical cluster. Because of the widespread use of Seinfeld and Pandis' book, we have keep our notation as close to theirs as possible. The log-slopes generated by equation (7) and shown in Plate 7 are in the range of 11 to 15 , and the number of molecules in a critical cluster for a surface tension of 20 dyne $\mathrm{cm}^{-1}$ and a nucleation rate of $10 \mathrm{~cm}^{-3} \mathrm{~s}^{-1}$ is about 10 . To obtain the classical nucleation equations in their standard from equation (7), the collision rates of monomers with clusters of all sizes are assumed to be the same so that $\beta_{i}$ can be removed from the above sum. This approximation is valid if the sticking coefficient between monomers and all cluster sizes is the same, making the $\beta_{\imath}$ values a slowly varying function of size. However, it is doubtful that each collision will result in sticking, especially in the limit of monomermonomer collisions where there are less degrees of freedom to remove the collisional energy without invoking a third body collision which would greatly reduce the rate constant for dimer formation. From equation (7) it is easy to evaluate the effect of lowering the rate constant. The dotted lines in Plate 7 were generated from equation (7) by lowering $\beta_{l}$ a factor of $10^{-6}$ below the collision rates. It is seen that the assumption (equal $\beta_{1}$ values), required for the validity of classical nucleation equations in their standard form, breaks down more readily at lower surface tension and higher nucleation rates. The reason for this is that, under these conditions, the back rate (evaporation rate) is much lower than the forward rate, diminishing the effect of the back rate in relation to the forward rate; i.e., resistance to nucleation is due primarily to the forward rate constants. In the limit where dimer formation is the rate-limiting step we would expect a (log) slope of 2 .

It is clear that the slopes generated by classical theory as shown in Plate 7 are not consistent with the observed slope unless the rate constants are radically different than those assumed in classical nucleation theory. As mentioned above, the concentration of the nucleating species, if different from the condensing species, must be less. Using smaller values of SVP in the above analysis does not materially change the above assertion regarding the slope; it does, of course, dramatically increase the nucleation rate above the observed rate.

Another way to estimate the slope of the nucleation curve is from the increase in ultrafine particles with time. Initially, the concentration $N_{v}$ of the nucleating species is zero. If we make the reasonable assumption that the initial rate of formation of $N_{v}$ is proportional to the reaction rate between $\mathrm{O}_{3}$ 
and $\alpha$-pinene, and if the concentrations of $\mathrm{O}_{3}$ and $\alpha$-pinene are nearly constant over the initial nucleation period, then

$$
N_{v}=\gamma k_{\mathrm{O}_{3}}\left\{\mathrm{O}_{3}\right\}\{\mathrm{HC}\} t,
$$

where $t$ is the time. We have further assumed that the aerosol surface area has not yet reached the point where it is a significant sink of $N_{v}$. It is often found that the nucleation rate $J$ can be represented as power law function of $N_{v}$, so that

$$
J=A N_{v}^{\beta}=A C_{\mathrm{l}}^{\beta} t^{\beta},
$$

where $C_{1}=\gamma k_{\mathrm{O}_{3}}\left\{\mathrm{O}_{3}\right\}\{\mathrm{HC}\}$. The total particle concentration $Z(t)$ is then

$$
Z(t)=\int J d t \propto \frac{A C_{1}^{\beta}}{\beta+1} t^{\beta+1} .
$$

The time in equation (10) is the time at which the critical nucleus of radius $r_{c}$ is formed (time of nucleation). If one neglects the Kelvin curvature term, the time $\tau$ for the particle to grow to the minimum detectable radius $r_{d}$ of the ultrafine $\mathrm{CN}$ counter can be written as

$$
\tau^{2}=t^{2}+\frac{2 C_{2}}{C_{1}}\left(r_{d}-r_{c}\right),
$$

where $C_{2}=4 \pi / v m, v$ is the mean thermal velocity and $m$ is the mass of the molecule. The critical radius is given by

$$
r_{c}=\frac{2 \sigma m}{k T \rho \ln \left(\frac{C_{1} t}{N_{\mathrm{svp}}}\right)},
$$

where $\sigma$ is the surface tension, $N_{\text {svp }}$ is the saturation concentration and $\rho$ is the density of the droplet. Equation (10) then becomes

$$
Z(\tau)=\frac{A C_{1}^{\beta}}{\beta+1}\left[\tau^{2}-\frac{2 C_{2}}{C_{1}}\left(r_{d}-r_{c}\right)\right]^{\frac{\beta+1}{2}} .
$$

Equation (13) reduces to equation (10) if the second term is much less than the first term. It is difficult to evaluate the second term rigorously because the surface tension and $N_{\text {svp }}$ are not generally known. However, solving equation (13) for the minimum detectable radius $(1.5 \mathrm{~nm})$ of the ultrafine $\mathrm{CN}$ counter and a range of values of $\sigma$ thought to be reasonable indicates that $\left(r_{d}-r_{c}\right)$ is zero $\left(r_{c}>r_{d}\right)$ or very small when $\tau$ is small, such that the first term usually dominates the solution. Therefore there is good reason to suspect that the measured ultrafine concentration is a valid indicator of the number of particles nucleated for the $\alpha$-pinene case. Plate 8 gives the measured ultrafine particle concentration at each second for four different experiments. November 9 is for the case when only $\alpha$-pinene and ozone were introduced into the chamber, and the observed slope $\beta$ is about 3.8. On November 18 and $11,0.5 \mathrm{ppb}$ and $6 \mathrm{ppb}$ of $\mathrm{SO}_{2}$ were introduced into the chamber in addition to $\alpha$-pinene and ozone. The addition of $0.5 \mathrm{ppb} \mathrm{SO}_{2}$, with the concentrations of $\alpha$-pinene and ozone (15 ppb and $110 \mathrm{ppb}$, respectively), nearly the same as on November 9, results in a much stronger nucleation event where the maximum $\mathrm{CN}$ concentration reached about $75 \times 10^{3}$ $\mathrm{cm}^{-3}$ as opposed to $20 \times 10^{3} \mathrm{~cm}^{-3}$ on November 9 (Plate 5). The nucleation began earlier in time, suggesting nucleation at lower reactant levels, and the slope of the nucleation line increased by a small amount. As discussed earlier, the total aerosol yield was similar to that observed on November 9, suggesting that $0.5 \mathrm{ppb} \mathrm{SO}$ affected the nucleation, but had little to no effect on the mass yield. On November 11 when 6 $\mathrm{ppb}$ of $\mathrm{SO}_{2}$ was added to the chamber with $15 \mathrm{ppb}$ of $\alpha-$ pinene and $110 \mathrm{ppb}$ of ozone, nucleation increased dramatically with the maximum $\mathrm{CN}$ concentration of about $390 \times 10^{3} \mathrm{~cm}^{-3} ;$ particles appeared in the ultrafine counter much sooner, and the slope increased to about 7.

We have also included data from November 3 when no $\alpha$ pinene was in the chamber and $\mathrm{SO}_{2}$ was oxidized by $\mathrm{OH}$ from photolysis of $\mathrm{CH}_{2} \mathrm{O}$. In this case, nucleation was presumably by oxidation of $\mathrm{SO}_{2}$ to sulfuric acid with subsequent nucleation of sulfuric acid aerosol. However, unlike the case when $\alpha$-pinene was present, growth of the particles to the minimum detectable size of the ultrafine counter was slower, indicating the gas-phase $\mathrm{H}_{2} \mathrm{SO}_{4}$ concentration was lower while the larger number of particles formed indicates a higher nucleation potential (lower SVP for sulfuric acid). The slope on November 3 is about 9 , in good agreement with that expected for sulfuric acid nucleation [Jaecker-Voirol and Mirabel, 1989], at the given RH and temperature. When 6 $\mathrm{ppb}$ of $\mathrm{SO}_{2}$ was added to $\alpha$-pinene and ozone, the nucleation may have been predominantly by sulfuric acid, but the condensable organic product was present to cause rapid growth to the minimum detectable size of the ultrafine particle counter.

On November 9, 11, and 18 (days with $\alpha$-pinene), particle growth was rapid, and modeling was able to predict that portion of the curve where $N_{v}$ should increase linearly with time. For November 3, particle growth was so slow that no particles were detected by the DMA during the part of the nucleation event shown, indicating loss of vapor to the particles was negligible (low aerosol surface area). The slopes $\beta$ indicated on Plate 8 are the graphically determined slopes minus one in keeping with equation (10). The slope as determined directly from the ultrafine particle counter in conjunction with equation $(10)$ is very close to that determined from the modeling and shown in Plate 5. The slope determined by the modeling is deemed to be more accurate because it does not assume the exponential form of the nucleation line and losses of $N_{\nu}$ to the walls and particles are taken into account.

We have purposely excluded the October 19 experiment from this comparison and have used only data from the November deployment. Between the October and November deployments all charcoal filters in the air purification system were replaced with new filters, and activated iodized filters were added to remove ammonia. In addition to filter replacement, improvements were made to the "tightness" of the air handling ducts. While there were no contaminants that we could identify with the instrumentation described earlier, there was evidence of contamination at the level that affected nucleation during the October deployment. For example, on October 16 an experiment involving $30 \mathrm{ppb}$ of cyclohexene and $135 \mathrm{ppb}$ of ozone in a "clean" chamber resulted in a weak but definite nucleation event where the maximum $\mathrm{CN}$ concentration was about $2000 \mathrm{~cm}^{-3}$. The same experiment repeated on November 10, but with an ozone concentration of $170 \mathrm{ppb}$, produced no nucleation. We do not believe that 


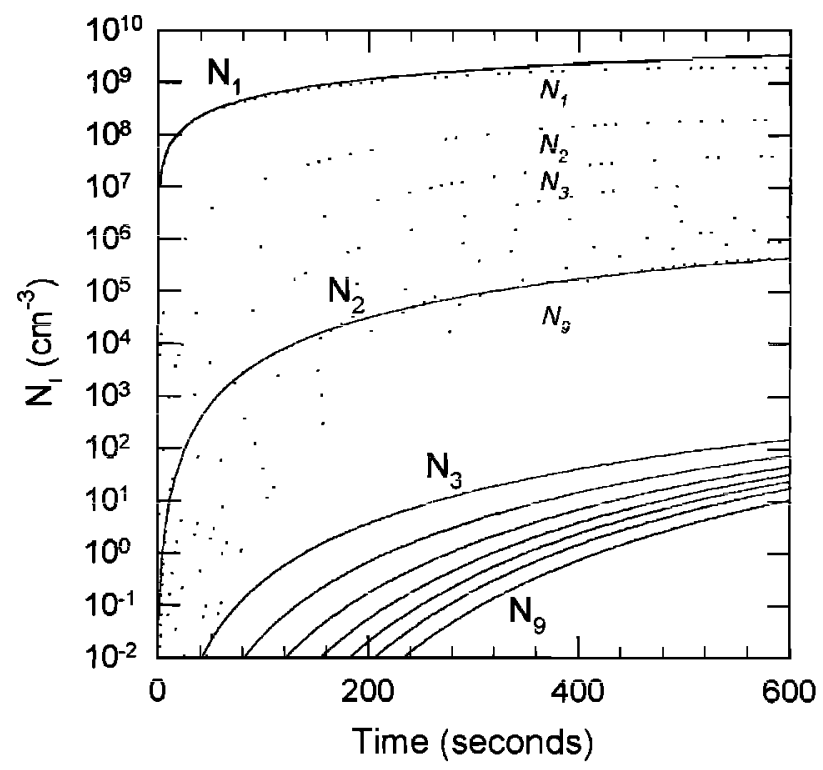

Figure 2. Transient concentration of clusters, $N_{l}$, with $i$ monomers. Dotted lines are for case where the rate constant is given by the collision rate (classical nucleation theory), and the solid lines assume that a stable dimer is formed once in every $10^{6}$ collisions (binary rate constant of $5.6 \times 10^{-16} \mathrm{~cm}^{-3} \mathrm{~s}^{-1}$ ).

whatever contaminant was responsible for the weak nucleation event observed in October would have been present in sufficient concentration to materially affect the conclusions about yield and SVP in the $\alpha$-pinene experiments, but it might have had a some effect on the magnitude of the nucleation event.

Since the effect of $\mathrm{SO}_{2}$ at the $0.5 \mathrm{ppb}$ level significantly increases the nucleation rate, the question arises as to whether or not $\mathrm{SO}_{2}$ contamination at or below the detectable level could be responsible for the observed nucleation on October 19 and November 9 rather than organic product(s) as assumed above. While we cannot conclusively rule out this possibility, the preponderance of evidence indicates that $\mathrm{SO}_{2}$ oxidation with subsequent nucleation of $\mathrm{H}_{2} \mathrm{SO}_{4}$ particles which act as condensation nuclei for the condensing organic product was not the responsible mechanism. This evidence includes the following: (1) As mentioned earlier, nucleation events consistent with the events we observed (without $\mathrm{SO}_{2}$ ) were recorded by Hatkeyama et al. [1989] in a $4 \mathrm{~m}^{3}$ chamber which could be evacuated and baked, and which was lined with borosilicate glass, using $15 \mathrm{ppb}$ of $\alpha$-pinene and $800 \mathrm{ppb}$ of ozone. It is unlikely that this experiment could have been contaminated with $\mathrm{SO}_{2}$. (2) The effective SVP of the condensing species is low enough to suspect homogeneous nucleation could occur without assuming the presence of $\mathrm{SO}_{2}$ as discussed above. (3) For the experiment using cyclohexene/ozone we saw no significant nucleation even though the product of the reactants were 4 times greater, implying larger $\mathrm{OH}$ and $\mathrm{H}_{2} \mathrm{SO}_{4}$ production if $\mathrm{SO}_{2}$ contamination were present. The $\mathrm{OH}$ yield $(0.85)$ for the $\alpha$ pinene/ozone and the yield $(0.65)$ for cyclohexene/ozone are about the same [Atkinson, 1994]. For the cyclohexene case, when small amounts of $\mathrm{SO}_{2}$ were added, we also saw large nucleation events.

Classical nucleation analysis assumes that the timescale for establishing a steady state population of clusters is very short compared the rate of change of the nucleation rate. In our experiments there is a relatively slow buildup of reactant products (compared to expansion and diffusion chambers normally used in nucleation experiments). There have been a number of papers which have investigated the transient timescale for the approach to steady state nucleation [see, e.g., Shi et al., 1990, and references therein]. In our case there is a predictable buildup of the condensing species due to a chemical reaction. For products with extremely low vapor pressure and high supersaturations the assumptions leading to the classical nucleation rate equations become increasingly questionable. First, for low concentrations of the nucleating species, the time to establish a steady state cluster distribution can be longer than the timescale on which the monomer population in our experiment is changing. Second, for high supersaturations, as implied in our experiment, the concentration of monomers required to establish the equilibrium cluster population can approach the concentration which remains as monomers.

In order to capture the time dependence of the nucleation and eliminate the numerous assumptions which are required to derive the classical nucleation rate equations, we have chosen to look directly at numerical solutions of the kinetic equations which govern the dynamics of the cluster population. These equations are given in Appendix A; here we only state some of the results. These equations, as used here, do not include the condensational loss of monomers to activated particles and hence only represent the initial stage of nucleation.

The equation governing the monomer concentration (equation (A1)) includes a source term for generation of the monomer from the ozone/ $\alpha$-pinene reaction with a molar yield of $\gamma$. The values of $\alpha$-pinene and ozone are $15 \mathrm{ppb}$ and $100 \mathrm{ppb}$, respectively. While many different cases were run, the cases discussed here all used a SVP of $0.002 \mathrm{ppb}$ and a molar yield of $7 \%$. The assumed molecular weight was 186 , and the surface tension was 20 dymes $\mathrm{cm}^{-1}$. Changing the surface tension can have a dramatic effect on the nucleation rate. Plate 7 indicates that a value of 20 dynes $\mathrm{cm}^{-1}$ may be as good as any other value we could have chosen. We consider two cases.

1. For the case where the rate constants are those given by the collision rate (assumption used to derive the classical nucleation equations), the dotted lines in Figure 2 show the development of the monomer $\left(N_{1}\right)$, dimer $\left(N_{2}\right)$, and i-mer $\left(N_{i}\right)$ concentrations for $i<10$. Monomers are assumed to be generated at a constant rate due to the $\alpha$-pinene/ozone reaction. The dotted lines in Figure 3 give the particle flux $J_{i}$ between $N_{t-1}$ and $N_{t}$; i.e. $J_{2}$ is the rate of dimer formation. The convergence of $J_{2}$ through $J_{10}$ indicates the rate at which the steady state flux is established between clusters 2 through 9. For the steady state assumption to hold at a given time all of the $J_{l}$ values must be nearly equal at that time. It is clear that the steady state assumption employed to derive the nucleation rate equations in their standard form is not valid over the first $400 \mathrm{~s}$. By the time the concentration of monomers reaches $2 \times 10^{9} \mathrm{~cm}^{-3}$, the nucleation flux reaches a steady state value of about $10^{6}$ particles $\mathrm{cm}^{-3} \mathrm{~s}^{-1}$. The flux out of the domain, $J_{10}$, is taken here to represent the nucleation rate. A curve of the flux, $J_{10}$, versus $N_{1}$ is shown in Figure 4 (labeled $\beta_{1}$ ) and has a log slope of about 10 . This slope is probably less than it would be had we carried out the 


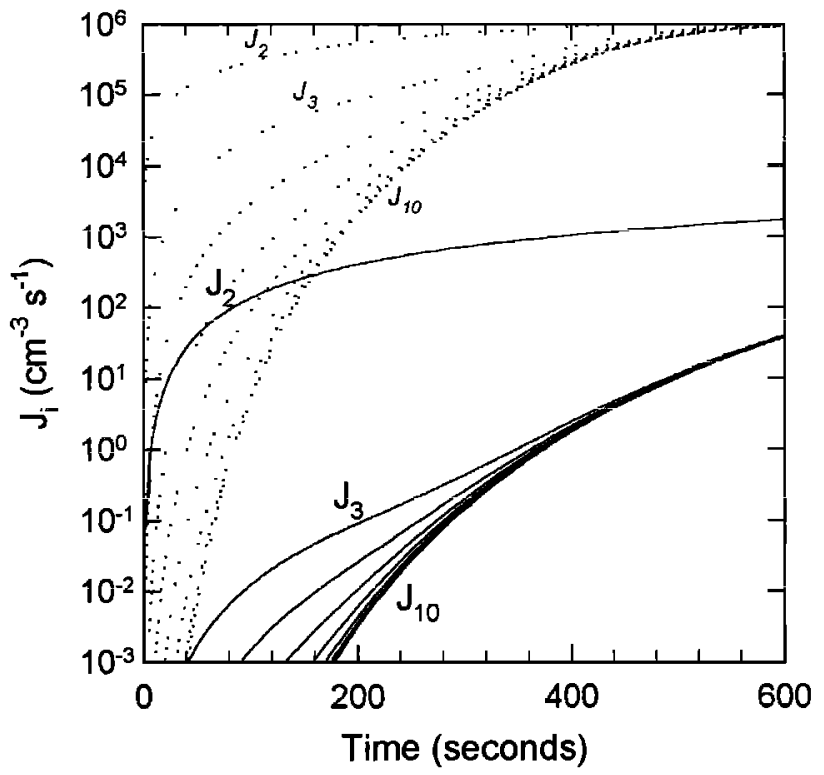

Figure 3. Flux of particles $J_{i}$ between $N_{i-1}$ and $N_{i}$; i.e., $J_{3}$ is flux of particles between dimers and trimers for same conditions as in Figure 2.

calculation including larger clusters; i.e., the critical size may well be larger than $i=10$, which is assumed here. We state without proof here that the curve of the nucleation rate verses $N_{1}$, is steeper during the period of increasing $N_{1}$, and less steep during decreasing $N_{1}$, than that given by steady state nucleation theory. For non-steady-state nucleation there is not a unique relationship between the nucleation rate and $N_{1}$, as assumed by steady state theory. As with the earlier steady state analysis (Plate 8), we were not able to find agreement with the observed slope of the nucleation line and observed nucleation rate using the usual forward and reverse rates in the solution of the kinetic equations.

2. It is interesting to consider the case where the rate constant for dimer and trimer formation is significantly smaller than the collision rate, as might be expected if a chemical reaction were required for their formation. Furthermore, if chemical binding is present, we might expect that the dimer and trimers thus formed would be stable (reverse rate is zero). The solid lines in Figure 2 shows the development of the dimer $\left(N_{2}\right)$, trimer $\left(N_{3}\right)$ and unstable cluster $\left(N_{i}, i>3\right)$ concentrations under the assumption that stable dimers are formed once in every $10^{6}$ collisions (binary rate constant of $5.6 \times 10^{-16} \mathrm{~cm}^{3} \mathrm{~s}^{-1}$ ) and trimers are formed in one out of $10^{3}$ collisions between dimers and monomers (binary rate constant of $6.2 \times 10^{-13} \mathrm{~cm}^{3} \mathrm{~s}^{-1}$ ). Compared to case 1 above, the cluster concentrations are now several orders of magnitude smaller, the monomer concentration $N_{1}$ is not depleted by the nucleation flux, giving a higher supersaturation with lower nucleation rates, and the critical cluster size is much smaller by virtue of the higher supersaturation (higher monomer concentration). Figure 3 (solid lines) gives the particle flux $J_{1}$ between $N_{i-1}$ and $N_{i}$; i.e., $J_{2}$ is the rate of dimer formation. The convergence of $J_{3}$ through $J_{9}$ indicates the rate at which the steady state flux is established between clusters 3 through 9 . Because of the small rate constant for dimer and trimer formation, the time for $J_{2}$ to come to equilibrium with $J_{3}$ is very long.
Figure 4 shows the nucleation line for four different cases where the fraction of collisions that result in dimer formation has been varied. The fraction of collisions which result in dimer formation is indicated on each curve $\left(10^{-6}\right.$ is for the case shown by solid lines in Figures 2 and 3 ). As the rate constant for dimer formation decreases, dimer formation becomes the rate-limiting step. If the flux were constant through all i-mers, we would then expect the slope of the nucleation line to be about 2 . This is not the case here because the fluxes have not reached steady state; i.e., $J_{2} \neq J_{3}$ (Figure 3 ).

It should be pointed out that while we saw a bending of the dotted lines of Plate 7 due to decreasing the rate of dimer (cluster) formation, the situation here is somewhat different. For the results shown in Figure 2-4 we are not only solving the kinetic equations, but we have also assumed that the dimers and trimers are stable (no evaporation).

The above exercise has been presented to illustrate that (1) under conditions where the nucleating species is continually increasing due to a chemical reaction, and where the monomer concentration available to establish the cluster distribution is small (very low SVP), it may require solution of the kinetic equations to capture the meaning of the nucleation data. For experiments on $\mathrm{H}_{2} \mathrm{SO}_{4}$ nucleation the vapor pressure is likely to be even lower than for these experiments making the transient behavior even more pronounced. (2) Given the SVP, nucleation line, nucleation rate, and supersaturation derived from our observations, we were not able to explain the observations in terms of the classical nucleation rate equations, in terms of the more general classical nucleation rate equations which only assume a steady state nucleation flux, or even in terms of solutions to the kinetic equations with the forward and reverse rate constants normally employed. Acceptable agreement could

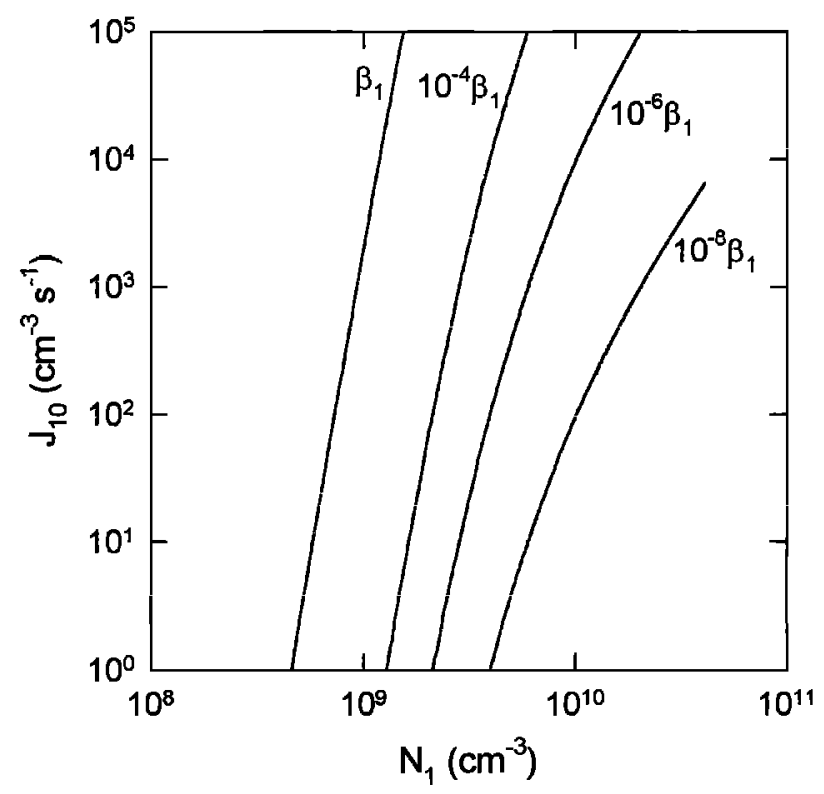

Figure 4. Nucleation rate verses the concentration of monomers. The curves labeled $10^{-4}, 10^{-6}$, and $10^{-8}$ are cases where one in $10^{-4}, 10^{-6}$, and $10^{-8}$ of collisions of monomers lead to formation of dimers. In the latter three cases the fraction of dimer-monomer collisions which lead to trimer formation is $10^{-3}$. 
undoubtedly be obtained by arbitrarily lowering the rate of dimer and/or adduct formation, but to do so at this point is of questionable value. It is clear that more research needs to be done on the early phase of the particle formation mechanism before we can understand nucleation in the $\alpha$-pinene/ozone system. This lends credence to the suggestion of Hoffmann et al. [1998] that nucleation in the $\alpha$-pinene/ozone system may not be described by classical nucleation theory where unstable clusters are formed statistically by condensation and evaporation processes. Much smaller slopes than those predicted by classical nucleation theory could occur if formation of stable adducts were required as the initial steps of particle formation and were the rate-limiting step.

\section{Conclusions}

Aerosol nucleation and growth were observed from the reaction products of $\alpha$-pinene and ozone, utilizing relatively low concentrations of $\alpha$-pinene $(15 \mathrm{ppb})$ and ozone (100 $\mathrm{ppb}$ ). Model simulations with a comprehensive sectional aerosol model which incorporated the relevant gas-phase chemistry shows that the observed evolution of the size distribution could be simulated within the accuracy of the experiment using only one condensable product. The nucleation rates used in the model were the measured nucleation rates. Good agreement between observed and modeled results was obtained when the yield was $5 \%$ to $6 \%$ and the SVP of the condensing species was about $0.01 \mathrm{ppb}$. The SVP must be viewed as an upper limit since lower values give equally good results. Also, the measured aerosol mass yicld curves behaved much as would be expected if the SOA resulted from condensation of a single species. While only a single condensing species was required to match observation, the possibility that there was more than one low SVP species contributing to the observed growth is a distinct possibility, in which case, the single component yield and SVP would represent an "effective" single component yield and SVP. Adding trace amounts of $\mathrm{SO}_{2}$ greatly increased the nucleation rate while having negligible effect on the overall yield of SOA.

We are unable to explain the observed nucleation in the $\alpha$ pinene/ozone system in terms of classical nucleation theory. The nucleation rate and, more importantly, the slope of the nucleation rate versus the vapor pressure of the nucleating species, would suggest that the nucleation rate in the $\alpha$ pinene/ozone system may be limited by the initial nucleation steps (i.e., dimer, trimer, or adduct formation). In the classical theory of nucleation the nucleation rate is determined by the embryo flux at the critical size, where the concentration of critical embryos is determined solely by the supersaturation and excludes the possibility that the rate-limiting step may be the rate of formation of dimers, trimers, etc. It is clear that more research needs to be done on the early phase of the particle formation mechanism before we can understand nucleation in the $\alpha$-pinene/ozone system.

In the atmosphere, nucleation will usually occur during periods of increasing concentration of low-volatility products, produced by gas-phase reactions. The very low concentrations of these products and the relatively high supersaturations achievable at low concentrations create a situation where the embryo population and particle flux between embryo classes may be far from the steady state values required by classical nucleation expressions (see Figure 3). It is therefore questionable whether the standard expressions for the nucleation rate as a function of the instantaneous monomer concentration is applicable to many atmospheric nucleation events. The nucleation rate may considerably lag (lead) the rate inferred from steady state nucleation theory during times of increasing (decreasing) monomer concentrations.

\section{Appendix A: Kinetic Equations Governing the Dynamics of the Cluster Population}

Here we state the equations which were used to produce the solutions shown in Figures 2-4. We assume, as is customary, that collisions between clusters are sufficiently rare to be neglected and that clusters are formed by addition and subtraction of monomers. The equation for the change in the monomer concentration $N_{1}$ is the following:

$$
\frac{d N_{1}}{d t}=Q-2 \beta_{1} N_{1}^{2}+2 \gamma_{2} N_{2}+\sum_{i=3}^{I} \gamma_{i} N_{i}-\sum_{i=2}^{I} \beta_{i} N_{1} N_{i},
$$

where $Q$ is the rate of formation of monomers, which for the solutions shown was

$$
Q=\gamma k\left[O_{3}\right][H C],
$$

$\gamma$ is the yield of condensing product, and $k$ is the rate constant for the reaction of $\mathrm{O}_{3}$ with $\alpha$-pinene. $\beta_{i}$ is the collision rate of the $i$-mer with monomers (forward rate constant), and $\gamma_{i}$ is the evaporation rate. $I$ is the largest cluster size. The upper limit, $I$, on the last term is for an open system; i.e., a flux of monomers out of the domain is allowed.

The equation for the change in the $i$-mer population is

$$
\frac{d N_{i}}{d t}=\beta_{i-1} N_{i-1} N_{1}-\gamma_{i} N_{i}-\beta_{i} N_{i} N_{1}+\gamma_{i+1} N_{i+1}
$$

When we terminate the series of equations, the last term of (A3) will be zero; and the next to last term gives the flux of particles out of the domain, taken to be the nucleation rate. The flux of cluster concentration between clusters is the difference between the forward and reverse rates. (For a closed system (no flux out of the domain) the next to last term is also zero, and the upper limit on the last term of equation (Al) is $I-1$. The required conservation of monomers in the case of a closed system is a good check on the numerics.)

The expressions for the forward and reverse rates were taken to be those given by Seinfeld and Pandis [1998], where the reverse rate is related to the SVP as modified by the Kelvin surface tension factor. The solutions to the system of $I$ equations, equations (A1) and (A3), were generated with a stiff equation solver.

Acknowledgments. This work was sponsored by the Office of Naval Research and the National Oceanographic Participation Program, Coastal and Marine Aerosol Transformation Processes Experiment. It also constitutes a contribution to the International Global Atmospheric Chemistry (IGAC) core project of the International Geosphere-Biosphere Programme (IGBP).

\section{References}

Atkinson, R., Gas-phase tropospheric chemistry of organic compounds, J. Phys. Chem. Ref. Data Monogr. 2, 215 pp., 1994. 
Christoffersen, T. S., et al., Cis-pinic acid, a possible precursor for organic aerosol formation from ozonolysis of $\alpha$-pinene, Atmos. Environ., 32, 1657-1661, 1998.

Fitzgerald, J. W., W. A. Hoppel, and F. Gelbard, A one-dimensional sectional model to simulate multicomponent aerosol dynamics in the marine boundary layer; 1, Model description, J. Geophys. Res., 103, 16,085-16,102, 1998a.

Fitzgerald, J. W., J. J. Marti, W. A. Hoppel, G. M. Frick, and F. Gelbard, A one-dimensional sectional model to simulate multicomponent aerosol dynamics in the marine boundary layer; 2, Model application, J. Geophys. Res., 103, 16,103-16,117, $1998 \mathrm{~b}$.

Gelbard, F., J. W. Fitzgerald, and W. A. Hoppel, A one-dimensional sectional model to simulate multicomponent aerosol dynamics in the marine boundary layer; 3 , Numerical methods and comparison with exact solutions, J. Geophys. Res., J03, 16,119-16,132, 1998.

Griffin, R. J., D. R. Cocker III, R. C. Flagan, and J. H. Seinfeld, Organic aerosol formation from the oxidation of biogenic hydrocarbons, J. Geophys. Res., 104, 3555-3567, 1999.

Guenther, A., et al., A global model of natural volatile organic compound emissions, J. Geophys. Res., 100, 8873-8892, 1995.

Hatakeyama, S., I. Katsuyuki, T. Fukuyama, and H. Akimoto, Reactions of ozone with $\alpha$-pinene and $\beta$-pinene in air: Yields of gaseous and particulate products, J. Geophys. Res., 94, 13,013$13,024,1989$.

Hoffmann, T., J. R. Odum, F. Bowman, D. Collins, D. Klockow, R. C. Flagan, and J. H. Seinfeld, Formation of organic aerosols from the oxidation of biogenic hydrocarbons, J. Atmos. Chem., 26, 189-222, 1997.

Hoffmann, T., R. Bandur, U. Marggraf, and M. Linscheid, Molecular composition of organic aerosols formed in the $\alpha$ pinene/ $\mathrm{O}_{3}$ reaction: Implications for new particle formation processes, J. Geophys. Res., 103, 25,569-25,578, 1998.

Hoppel, W., G. Frick, P. Caffrey, L. Pastemack, T. Albrechcinski, J. R. Ambrusko, W. Sullivan, D. Hegg and S. Gao, Report on the characterization of Calspan's $600 \mathrm{~m}^{3}$ chamber in preparation for the NOPP aerosol process experiments, Rep. MR 6110-99-8370, 58 pp., Nav. Res. Lab., Washington, D. C., 1999.

Jaecker-Voirol, A., and P. Mirabel, Heteromolecular nucleation in the sulfuric acid-water system, Atmos. Environ., 23, 2053-2057, 1989.

Jang, M., and R. M. Kamens, Newly characterized products and composition of secondary aerosols from the reaction of $\alpha$-pinene with ozone, Atmos. Environ., 33, 459-474, 1999.

Leaitch, W. R., J. W. Bottenheim, T. A. Biesenthal, S.-M. Li, P. S. K. Liu, K. Asalian, H. Dryfhout-Clark, and F. Hopper, A case study of gas-to-particle conversion in an eastern Canadian forest, J. Geophys. Res., 104, 8095-8111, 1999.

Odum, J. R., T. Hoffmann, F. Bowman, D. Collins, R. C. Flagan, and J. H. Seinfeld, Gas/particle partitioning and secondary organic aerosol yields, Environ. Sci. Technol., 30, 2580-2585, 1996.

Seinfeld, J. H., and S. N. Pandis, Atmospheric Chemistry and Physics From Air Pollution to Climate Change, 1326 pp., John Wiley, New York, 1998.

Shi, G., J.H. Seinfeld, and K. Okuyama, Transient kinetics of nucleation, Phys. Rev., 34, 2101-2108, 1990.

Viisanen, Y., and R. Strey, Homogeneous nucleation rates for nbutanol, J. Chem. Phys., 101, 7835-7843, 1994.

Virkkula, A., R. Van Dingenen, F. Raes, and Jens Hjorth, Hygroscopic properties of aerosol formed by oxidation of limonene, $\alpha$-pinene, and $\beta$-pinene, J. Geophys. Res., 104, 3569 $3579,1999$.

Yu, J., D. R. Cocker III, R. J. Griffin, R. C. Flagan, and J. H Seinfeld, Gas-phase ozone oxidation of monoterpenes: Gaseous and particulate products, J. Atmos. Chem., 34, 207-258, 1999.

T. Albrechcinski, J. Ambrusko, and W. Sullivan, CalspanUniversity of Buffalo Research Center, Buffalo, NY 14225.

P.Caffrey, J. Fitzgerald, G. Frick and W. Hoppel, Naval Research Laboratory, Code 7228, 4555 Overlook Ave. SW, Washington, D. C. 20375. (whoppel@ccf.nrl.navy.mil.)

C. Cantrell, National Center for Atmospheric Research, 1850 Table Mesa Drive, Boulder, CO 80303.

S. Gao and D. Hegg, University of Washington, Department of Atmospheric Sciences, Box 351640, Seattle, WA 98195-1640.

R. Leaitch and N. Shantz, Air Quality Monitoring Division, Meteorological Service of Canada, 4905 Dufferin Street Downsview, Ontario M3H 5T4, Canada.

L. Pasternack, Naval Research Laboratory, Code 6111, 4555 Overlook Ave. SW, Washington, D. C. 20375.

(Received September 7, 2000; revised December 18, 2000; accepted January 8, 2001.) 